\title{
Identification of possible targets of the Aspergillus fumigatus CRZ1 homologue, CrzA
}

Frederico M Soriani ${ }^{1}$, Iran Malavazi ${ }^{3}$, Marcela Savoldi$^{1}$, Eduardo Espeso ${ }^{4}$, Taísa M Dinamarco ${ }^{1}$, Luciano AS Bernardes ${ }^{1}$, Márcia ES Ferreira ${ }^{1}$, Maria Helena S Goldman², Gustavo H Goldman ${ }^{1 *}$

\begin{abstract}
Background: Calcineurin, a serine/threonine-specific protein phosphatase, plays an important role in the control of cell morphology and virulence in fungi. Calcineurin regulates localization and activity of a transcription factor called CRZ1. Recently, we characterize Aspergillus fumigatus CRZ1 homologue, AfCrzA. Here, we investigate which pathways are influenced by A. fumigatus AfCrzA during a short pulse of calcium by comparatively determining the transcriptional profile of $A$. fumigatus wild type and $\triangle A f c r z A$ mutant strains.
\end{abstract}

Results: We were able to observe 3,622 genes modulated in at least one timepoint in the mutant when compared to the wild type strain (3,211 and 411 at 10 and 30 minutes, respectively). Decreased mRNA abundance in the $\triangle c r z A$ was seen for genes encoding calcium transporters, transcription factors and genes that could be directly or indirectly involved in calcium metabolism. Increased mRNA accumulation was observed for some genes encoding proteins involved in stress response. AfCrzA overexpression in A. fumigatus increases the expression of several of these genes. The deleted strain of one of these genes, AfRcnA, belonging to a class of endogenous calcineurin regulators, calcipressins, had more calcineurin activity after exposure to calcium and was less sensitive to menadione $30 \mu \mathrm{M}$, hydrogen peroxide $2.5 \mathrm{mM}$, EGTA $25 \mathrm{mM}$, and $\mathrm{MnCl}_{2} 25 \mathrm{mM}$. We constructed deletion, overexpression, and GFP fusion protein for the closely related A. nidulans AnRcnA. GFP::RcnA was mostly detected along the germling, did not accumulate in the nuclei and its location is not affected by the cellular response to calcium chloride.

Conclusion: We have performed a transcriptional profiling analysis of the A. fumigatus $\triangle A f c r z A$ mutant strain exposed to calcium stress. This provided an excellent opportunity to identify genes and pathways that are under the influence of AfCrzA. AfRcnA, one of these selected genes, encodes a modulator of calcineurin activity. Concomitantly with A. fumigatus AfrcnA molecular analysis, we decided to exploit the conserved features of $A$. nidulans calcineurin system and investigated the A. nidulans AnRcnA homologue. A. nidulans AnRcnA mutation is suppressing CnaA mutation and it is responsible for modulating the calcineurin activity and mRNA accumulation of genes encoding calcium transporters.

\section{Background}

The phosphatase calcineurin is a heterodimeric protein composed by a catalytic subunit $\mathrm{A}$ and a regulatory subunit $B$ [1]. In fungi, calcineurin plays an important role in the control of cell morphology and virulence [1-4]. Calcineurin regulates morphogenesis, $\mathrm{Ca}^{+2}$ homeostasis, and stress-activated transcription in Saccharomyces cerevisiae $[1,5]$. In pathogenic fungi, calcineurin affects

\footnotetext{
* Correspondence: ggoldman@usp.br

${ }^{1}$ Centro de Ciência e Tecnologia do Bioetanol and Faculdade de Ciências Farmacêuticas de Ribeirão Preto Universidade de São Paulo, São Paulo, Ribeirão Preto, 14040-903, Brazil
}

C 2010 Sorian et al; licensee BioMed Central Ltd. This is an Open Access article distributed under the terms of the Creative Commons Attribution License (http://creativecommons.org/licenses/by/2.0), which permits unrestricted use, distribution, and reproduction in any medium, provided the original work is properly cited. virulence, morphogenesis, and antifungal drug action [1,6-9]. Inactivation of calcineurin in Cryptococcus neoformans affects growth at $37^{\circ} \mathrm{C}$ and hyphal elongation during mating and haploid fruiting [10-13]. Reduced virulence and absence of growth in serum are also observed in Candida albicans depleted in the calcineurin activity $[11,14,15]$. In $A$. fumigatus, calcineurin inactivation decreases the virulence and provides decreased filamentation and no growth in serum $[9,16]$.

Calcineurin regulates the localization and activity of the transcription factor Crz1p by dephosphorylating it [17]. Upon increase in cytosolic calcium, calcineurin 
dephosphorylates Crz1p, allowing its nuclear translocation $[17,18]$. Crz1p has a $\mathrm{C} 2 \mathrm{H} 2$ zinc finger motif that binds to a CDRE (calcineurin-dependent response element) in the promoters of genes that are regulated by calcineurin and calcium [19]. Mutants of S. cerevisiae inactivated in CRZ1 display hypersensitivity to chloride and chitosan, a defective transcriptional response to alkaline stress, and cellular morphology and mating defects [17,19-21]. Inactivation CRZ1 mutants of Schizosaccharomyces pombe ( $\Delta$ prz1) are hypersensitive to calcium and have decreased transcription of the Pmc1 Ca ${ }^{+2}$ pump [22]. C. albicans homozygotes $\operatorname{crz} 1 \Delta / \Delta$ are moderately attenuated for virulence and sensitive to calcium, lithium, manganese, and sodium dodecyl sulfate $[18,23,24]$. A. fumigatus CRZ1 mutant, $\triangle c r z A$, is avirulent and has decreased conidiation [16,25]. Its hypersensitivity to calcium and manganese is probably due to the reduced expression of calcium transporter mRNAs under high concentrations of calcium [16].

Here, we investigate which pathways are influenced by A. fumigatus AfCrzA during a short pulse of calcium by comparatively determining the transcriptional profile of A. fumigatus wild type and $\triangle A f c r z A$ mutant strains. Our results revealed several possible novel targets for AfCrzA, including AfRcnA, a member of the conserved calcineurin-binding proteins, the calcipressins. Besides the transcriptional profiling of the A. fumigatus $\triangle A f c r z A$, we also showed the molecular characterization of Aspergilli RcnAs.

\section{Results and Discussion \\ Transcriptional profiling of the $A$. fumigatus $\Delta c r z A$ mutant strain}

To have a better understanding of which genes are influenced by $A$. fumigatus AfCrzA during exposure to calcium, we performed competitive microarray hybridizations using RNA obtained from the wild type and $\triangle A f c r z A$ strains after short pulses (10 and 30 minutes) of $200 \mathrm{mM}$ calcium chloride. RNA obtained from wild type mycelia exposed to 10 and 30 minutes calcium was taken as reference. Thus, total RNA extracted from these cultures was used to synthesize fluorescent-labeled cDNAs for competitive microarray hybridizations. In these experiments, the main aim was to focus on genes that have increased or decreased mRNA expression in the absence of AfCrzA. We were able to observe 3,622 genes modulated in at least one timepoint in the mutant when compared to the wild type strain (3,211 and 411 at 10 and 30 minutes, respectively). The large difference between the number of genes modulated at 10 and 30 minutes (about eight-times more at 10 minutes) suggests $A$. fumigatus responds rapidly to calcium stressing conditions. The full dataset was deposited in the Gene Expression Omnibus (GEO) from the National Center of Biotechnology Information (NCBI) with the number GSE15432 http://www.ncbi.nlm.nih.gov/projects/geo/ query/acc.cgi?acc=GSE15432. Previously, to evaluate the effect of calcium on global A. fumigatus gene expression, we performed competitive microarray hybridizations using RNA obtained from the wild type strain before and after a short pulse (10 minutes) of $200 \mathrm{mM}$ calcium chloride (Soriani et al., 2008). Statistical analysis of this dataset identified a total of 863 genes that displayed modulation. The large difference in genes whose expression is modulated between this dataset and the current dataset using a comparison between $\triangle c r z A$ and the wild type strains emphasizes the pleiotropic role played by $A$. fumigatus calcineurin-CrzA in the calciummediated signal transduction pathways. We are currently investigating the importance of this difference.

We observed differential regulation of genes involved in a variety of cellular processes and specific modulation of these functions is therefore likely to be implicated with A. fumigatus adaptation to high concentrations of calcium (Additional files 1 and 2, Tables S1 and S2, respectively, show the genes with log ratios more than or equal to 1 or less than or equal to 1 in at least in one time point, respectively). These genes were classified into COG functional categories http://www.ncbi.nlm.nih. gov/COG/. However, we were not able to observe any significant enrichment for a specific COG category (Additional files 1 and 2, Tables S1 and S2, repectively). We noted decreased mRNA abundance in the $\triangle A f c r z A$ of several genes involved in calcium transport, such as the vacuolar $\mathrm{H}^{+} / \mathrm{Ca}^{+2}$ (Afu2g07630), calcium-translocating P-type ATPase (PMCA-type, Afu3g10690), and calcium-transporting ATPase 1 (PMC1, Afu7g01030). We also observed decreased mRNA accumulation when the $\triangle A f c r z A$ strain was exposed to calcium of genes encoding several transcription factors [CtfA (Afu4g03960), RfeF (Afu4g10200), and ZfpA (Afu8g05010)], and genes that could be directly or indirectly involved in calcium metabolism [such as a phospholipase D (Afu2g16520), two peptidyl-prolyl cis-trans isomerases (Afu5g13350 and Afu2g03720), a calcineurin binding protein (Afu2g13060), a Bar adaptor protein (Afu3g14230), and a potential regulator of cytoskeleton and endocytosis, homologue of mammalian amphiphysin. Interestingly, a chitin synthase A (Afu2g01870) also showed decreased mRNA accumulation in the $\triangle A f c r z A$ strain background. Cramer et al. [26] have shown that the calcineurin pathway plays an important role in cell wall biosynthesis in A. fumigatus, and that calcineurin and AfCrzA inactivation mutants are more sensitive to specific cell wall inhibitors, such as caspofungin. However, in contrast to our results these authors have observed an increased and decreased mRNA accumulation of chitin synthase $\mathrm{A}$ in the $\triangle A f c r z A$ and $\triangle A f c a l A$ mutant strains, respectively. 
Several of the genes above mentioned (such as Afu2g16520, Afu2g13060, Afu3g14230, Afu4g10200, Afu8g05010, and Afu3g10690) have also been observed by Soriani et al. [16] as more expressed upon exposure of $A$. fumigatus to calcium. We have also previously observed that $z f p A$ (Afu8g01050) has increased mRNA accumulation that is dependent on the cyclic AMP-protein kinase A signaling pathway during adaptation to voriconazole [26]. Thus, it is plausible that $z f p A$ is related to a transcriptional network controlled by calcineurin-CrzA that has a key role in mediating cellular stress responses.

We observed increased mRNA accumulation when the $\triangle A f c r z A$ strain was exposed to calcium of genes encoding a class $V$ chitinase (Afu7g08490), an exo- $\beta$-1,3-glucanase (Afu2g00430), an AAA family ATPase (Afu4g04800), a cation diffusion facilitator 3, a multidrug resistance protein (Afu4g01140), a TOR signalling pathway protein TipA (Afu2g07540), an inositol polyphosphate phosphatase (Afu5g02140), a representative of the Hsp9-12 heat shock protein Scf1 (Afu1g17370), and a protein phosphatase $2 \mathrm{C}$ (Afu4g00720). Again, the increased expression of the chitinase and exo- $\beta$-1,3-glucanase could help to explain the increased sensitivity of A. fumigatus $\triangle A f c r z A$ strain to caspofungin [26]. Interestingly, some of these genes are involved in stress response, such as: (i) the Scf1 homologue (Afu117370), a plasma membrane localized protein that protects membranes from desiccation and it is induced by heat shock, oxidative stress, osmostress, stationary phase entry, glucose depletion, oleate and alcohol, and is regulated by the HOG and Ras-Pka pathways http://www. yeastgenome.org[27]; (ii) TipA (Afu2g07540), a component of the TOR (target of rapamycin) signaling pathway, that interacts physically and genetically with Tap42p, which regulates protein phosphatase 2A [28]; and (iii) a protein phosphatase $2 \mathrm{C}$ (Afu4g00720), important physiological regulator of cell growth and of cellular stress signaling [29]. The increased mRNA accumulation of these genes could mean that they are directly or indirectly repressed by AfCrzA and can open new frontiers for studying biochemical pathways that are under influence of the A. fumigatus calcineurin-CrzA pathway.

We then used RT-PCR, both to assess the reliability of the microarray hybridizations and to document mRNA expression from selected genes of interest in the wild type, $\triangle A f c a l A$ and $\triangle A f c r z A$ mutant backgrounds, choosing five genes (three and two with decreased and increased mRNA accumulation in the microarray experiments, respectively) to analyze after 10 and 30 minutes in the presence of $200 \mathrm{mM} \mathrm{CaCl} 2$. We had previously shown that five other genes (such as Afu8g05010, C2H2 finger domain protein; Afu4g03960, C6 transcription factor; Afu2g16520, phospholipase D; and Afu2g05330, vacuolar $\mathrm{H}^{+} / \mathrm{Ca}^{+2}$ exchanger; and Afu2g13060, calcineurin binding protein), identified here in this screening had induced mRNA accumulation in the presence of calcium, but reduced in $\triangle A f c r z A$ mutant background [16]. Expressing the results as fold induction relative to expression prior to calcium exposure, all values were in strong agreement with array hybridisation data (Figure 1). Comparisons between the gene expression variation estimated by microarray and real-time RT-PCR were performed by calculating both Pearson's $\left(R_{\mathrm{P}}\right)$ and Spearman's $\left(R_{\mathrm{S}}\right)$ correlation coefficients for the log2 ratios obtained by these two approaches. Positive correlation was observed for both $R_{\mathrm{P}}$ and $R_{\mathrm{S}}$ in all nine genes (Figure 1) [16]. Furthermore, the value of either $R_{\mathrm{P}}$ or $R_{\mathrm{S}}$ was above 0.70 (indicating moderate-to-strong correlation). Thus, these data suggest that our approach was able to provide information about $A$. fumigatus gene expression modulation with a considerably high level of confidence.

It is very impressive the mRNA accumulation levels of the Hsp9-12 heat shock protein Scf1 homologue (Afu1g17370): about 100 and 1000 times more in the $\triangle c r z A$ and $\triangle c a l A$ than in the wild type, respectively (Figure 1E). A. fumigatus has two Hsp12 homologues, Afu1g17370 (e-value $=3.7 \mathrm{e}-10 ; 45$ and 57 identity and similarity, respectively) and Afu6g12450 (e-value $=3.1 \mathrm{e}$ 9; 39 and 56 identity and similarity, respectively). Interestingly, the S. cerevisiae HSP12 was also shown to be induced by calcium but in contrast to the $A$. fumigatus homologue, the $S$. cerevisiae gene is repressed when calcium+FK506 were added and accordingly repressed in the $\triangle C R Z 1$ background [30]. Thus, it remains to be determined the roles played by calcineurin, AfCrzA, and AfHsp12p during adaptation of $A$. fumigatus to calcium stress.

Recently, Hagiwara et al. [31] identified and characterized the $A$. nidulans AncrzA gene. They performed an in silico analysis by using MEME (Motif-based sequence analysis tools; http://meme.sdsc.edu/meme4_1_1/intro. html) of the possible presence of a CDRE-like consensus motif in the promoter regions of 25 AnCrzA-dependent genes. By analyzing their promoter regions, 5'-G[T/G] GGC[T/A]G[T/G]G-3' was presumed to be the consensus sequence for the $A$. nidulans AnCrzA-dependent genes. By using a combination of MEME analysis and the $A$. nidulans CDRE consensus as a guide, we were able to identify in the AfrcnA, AfrfeF, AfBAR, and the $A$. fumigatus phospholipase D promoter regions (about 500 bp upstream ATG) the following CDRE motifs: (i) AfrcnA (5'-GTTGGTGAG-3', -314 bp upstream ATG starting point), (ii) AfrfeF (5'GTGGCTGAT-3', -184 bp upstream ATG), (iii) AfBAR (5'-GTGGCTGAC-3', -309 bp upstream ATG), and (iv) A. fumigatus phospholipase D (5'-GTTGGAGAG-3', -239 upstream ATG). We 
A.

B.

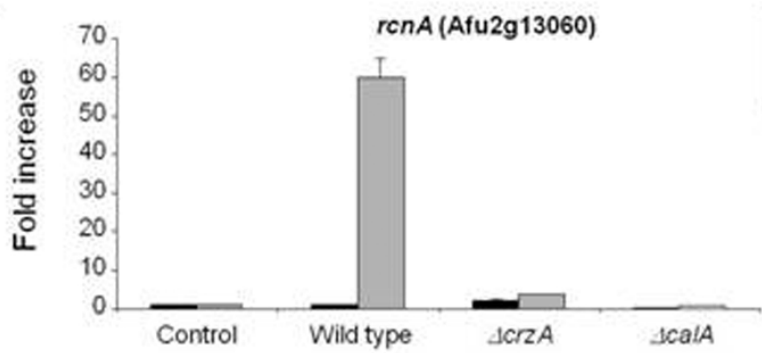

rfeF (Afu4g10200)

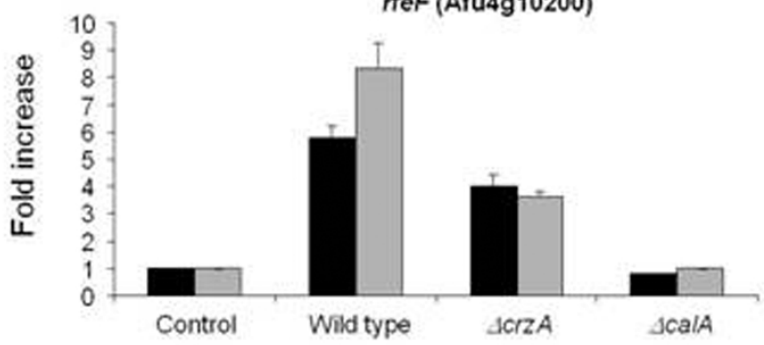

C.

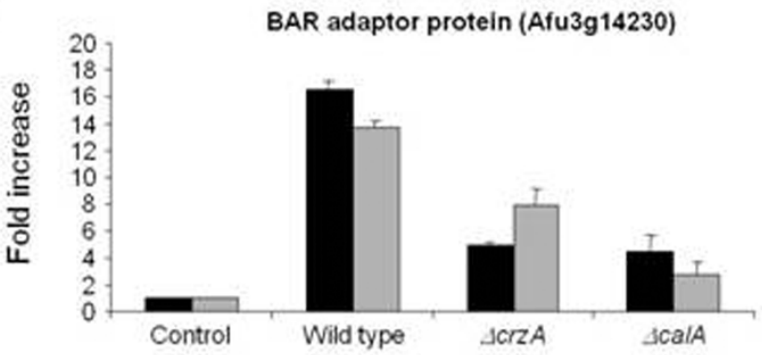

D.

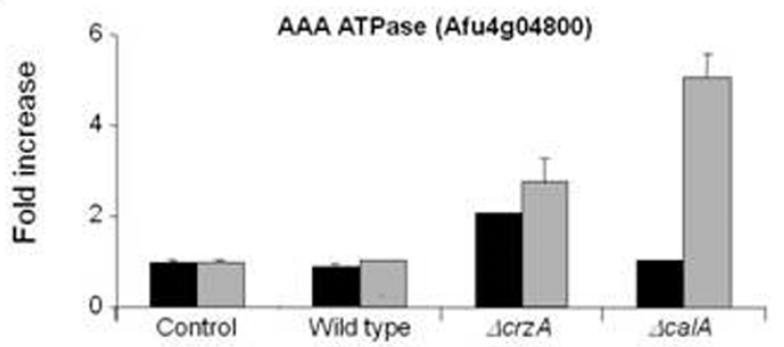

E.

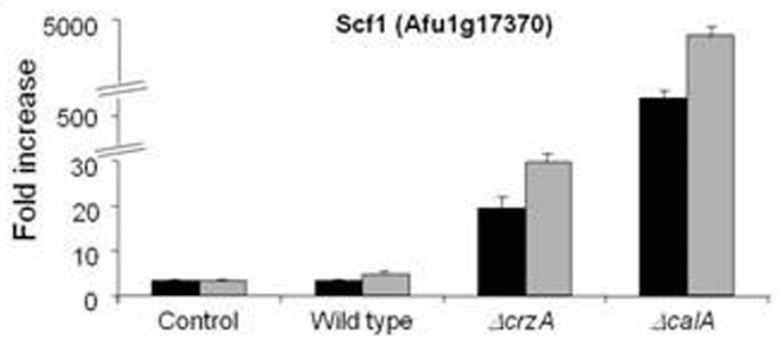

Figure 1 Validation of the genes observed as more or less induced in the $\boldsymbol{A}$. fumigatus $\triangle A f c r z A$ mutant. Fold increase in mRNA levels after the incubation with $200 \mathrm{mM} \mathrm{CaCl}$ for 10 and 30 minutes of (A) AfrcnA (Afu2g13060), (B) AfrfeF (Afu4g10200), (C) Af BAR adaptor protein (Afu3g14230), (D) Af AAA ATPase (Afu4g04800), and (E) AfScf1 (Afu1g17370). Real-time RT-PCR was the method used to quantify the mRNA. The measured quantity of the mRNA in each of the treated samples was normalized using the $C_{T}$ values obtained for the $\beta$-tubulin (Afu1g10910) mRNA amplifications run in the same plate. The relative quantitation of all the genes and tubulin gene expression was determined by a standard curve (i.e., $C_{T}$-values plotted against logarithm of the DNA copy number). The results are the means \pm standard deviation of four sets of experiments. The values represent the number of times the genes are expressed compared to the corresponding control strain grown before adding $200 \mathrm{mM} \mathrm{CaCl}_{2}$ (represented absolutely as 1.00). 
compared these motifs with the promoter regions (about 500 bp upstream ATG) of 32 repressed genes described in Additional file 1, Table S1, and this analysis suggested 5'-GT[T/G]G[G/C][T/A]GA[G/T]-3' as the CDRE-consensus sequence for $A$. fumigatus AfCrzA-dependent genes. We also analyzed $A f s c f 1$ and Af AAA ATPase genes and found the following CDRE-like motifs: (i) Afscf1 (5'-GGGAACGAA-3', -376 bp upstream ATG), and (ii) Af AAA ATPase (5'-GAAGACGAG-3', -19 bp upstream ATG). Again, we compared these motifs with the promoter regions (about $500 \mathrm{bp}$ upstream ATG) of 109 induced genes described in Additional file 2, Table $\mathrm{S} 2$, and we were able to propose as a putative CDRE consensus for gene repressed by $A f C r z A$, the sequence 5'-G[A/G][A/G][A/G]ACGA[A/G]-3'. It remains to be experimentally determined if these sequences are really important for AfCrzA gene regulation, both for gene induction and repression.

Prior to this work, a study analysing global gene expression regulated by the calcineurin/Crzlp signaling pathway in S. cerevisiae had attempted to identify genes regulated by calcium and sodium [30]. Calcineurin activation induced 153 genes involved in cell wall biosynthesis, ion homeostasis, vesicle trafficking, lipid synthesis, and protein degradation. A notable similarity was observed by the authors in the gene expression patterns of FK506-treated cells and crz1 cells, suggesting that Crz1p is required for most calcineurin-dependent changes in gene expression. Recently, Soriani et al. [16] opted to an alternative strategy, exposing A. fumigatus wild type strain to a short pulse with a high concentration of calcium, and arbitrarily choosing several genes that were less or more expressed in the microarray hybridization analyses to verify their expression in the wild type, and $\triangle A f c a l A$ and $\triangle A f c r z A$ mutant strains by real-time RT-PCR. Thus, these authors were able to determine if the expression of these genes was dependent on calcineurin and/or AfCrzA. They verified that the majority of these genes suffered blocking of mRNA accumulation in the $\triangle A f c r z A$ background. The results shown here added more information about the transcriptional network involved in the calcineurin-AfCrzA in response to calcium.

\section{Construction of Aspergilli CrzA overexpression strains}

Overexpression of AfCrzA could reveal genes regulated by the calcineurin-AfCrzA pathway. Accordingly, we constructed an overexpression A. fumigatus AfCrzA strain by using the alcA promoter. The $A$. nidulans alcA promoter homologously replaced the $A f c r z A$ promoter (for details of the construction, see Methods section). The alcA promoter is repressed by glucose, derepressed by glycerol and induced to high levels by ethanol or Lthreonine [32]. When A. fumigatus is grown on glycerol $2 \%$ supplemented either with ethanol $2 \%$ or threonine
$100 \mathrm{mM}$, AfcrzA mRNA accumulation in increased about 3.8- and 3.6-times, respectively compared to growth on glucose $4 \%$ (Figure $2 \mathrm{~A}$, left and right graphs). As expected, when the $A f c r z A$ is repressed in the presence of glucose, the alcA::AfcrzA strain is more sensitive to calcium (Figure 2B); however, surprisingly high levels of AfCrzA mRNA accumulation also make the alcA::AfcrzA strain more calcium-sensitive (Figure 2B). These results suggest that CrzA overexpression could potentially disturb the mRNA accumulation of genes that are important for the calcium homeostasis in the cell, thus disturbing the calcium metabolism into the cell and consequently the growth in the presence of increasing calcium concentrations. To test this hypothesis we used real-time RT-PCR to verify the mRNA levels of selected genes observed as having decreased mRNA and increased accumulation (see Additional file 1, Table S1). As it can be seen in Figure 3, all tested genes to different extent have increased mRNA accumulation when the $A f c r z A$ is overexpressed. The Af AAA ATPase (Afu4g04800) and AfScf1 (Afu1g17370) have increased mRNA accumulation when the $\triangle A f c r z A$ was exposed to calcium suggesting they are repressed by AfCrzA (see Figures 1E-F). We expected their mRNA accumulation would be reduced when AfCrzA is overexpressed. However, the mRNA levels of these genes were lower in the alcA::AfcrzA than in the $\triangle A f c r z A$ mutant strain (compare Figures 1E-F with Figures 3I-J), what could indicate that AfCrzA is partially controlling the mRNA accumulation levels of these genes. The genes encoding $A f p m c B$ (Afu3g10690), AfrcnA (Afu2g13060), AfrfeF (Afu4g10200), and AfBAR adaptor protein (Afu3g14230) are about 14, 16, 13, and 250 times more expressed in the alcA::AfcrzA mutant than the wild type strain, respectively (Figure $3 \mathrm{~B}$ and $3 \mathrm{~F}-\mathrm{H}$ ). The $A f p m c B$ (Afu3g10690) gene is A. fumigatus homologue of the yeast $P M C 1$, a vacuolar $\mathrm{Ca}^{+2}$ ATPase involved in depleting cytosol of $\mathrm{Ca}^{+2}$ ions and preventing growth inhibition by activation of calcineurin in the presence of elevated concentrations of calcium [33]. The increased expression of this gene suggests AfCrzA is controlling directly or indirectly its expression. Furthermore, the increased mRNA accumulation of these calcium transporter-encoding genes is quite consistent taking into consideration the dramatic stress condition caused by the sudden increase in calcium concentration that needs either to be removed from the cytoplasm or transported to vacuoles. Considering the growth inhibition of the Aspergilli alcA::AfcrzA strain under high-Ca ${ }^{+2}$ conditions (see Figures 2A-B), one possible interpretation of these results is that the AfCrzA overexpression can inhibit the function of another factor that is necessary for growth under high $-\mathrm{Ca}^{+2}$ conditions. 
A.

\section{crzA (Afu1g06900)}
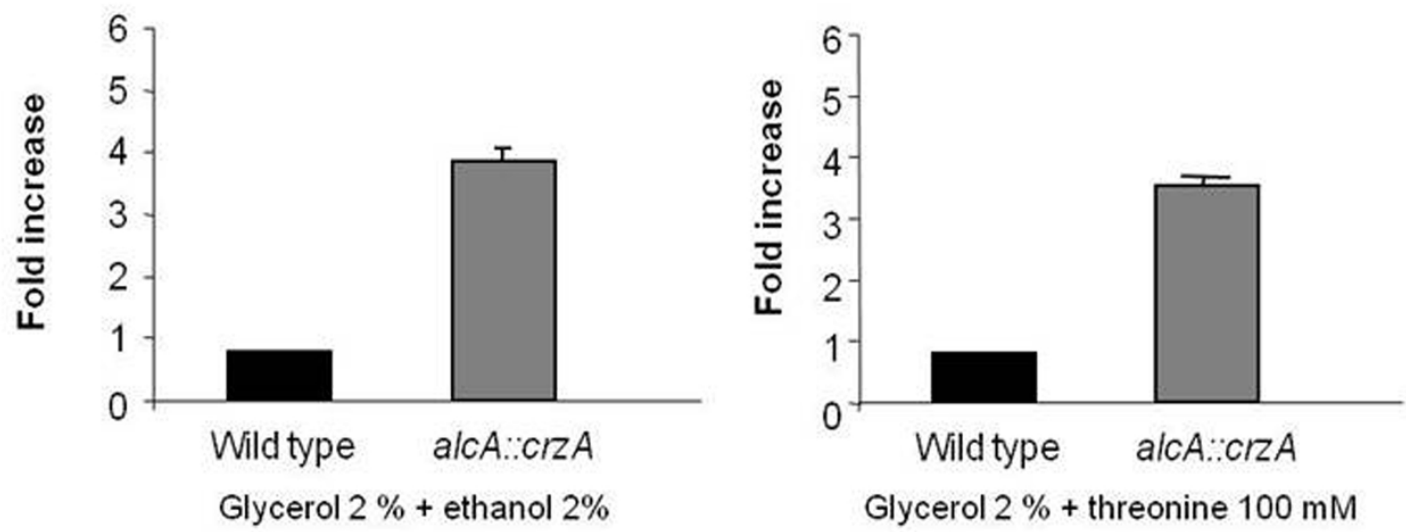

B.

Glucose

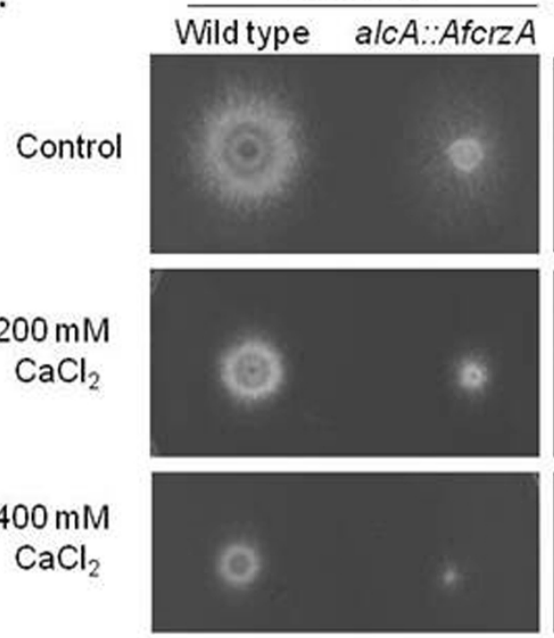

Glycerol

Glycerol + threonine
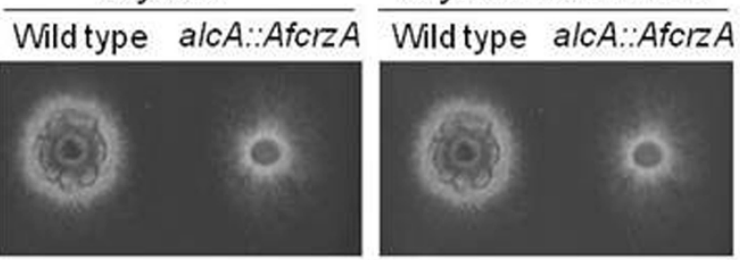

Glycerol $2 \%$ + threonine $100 \mathrm{mM}$
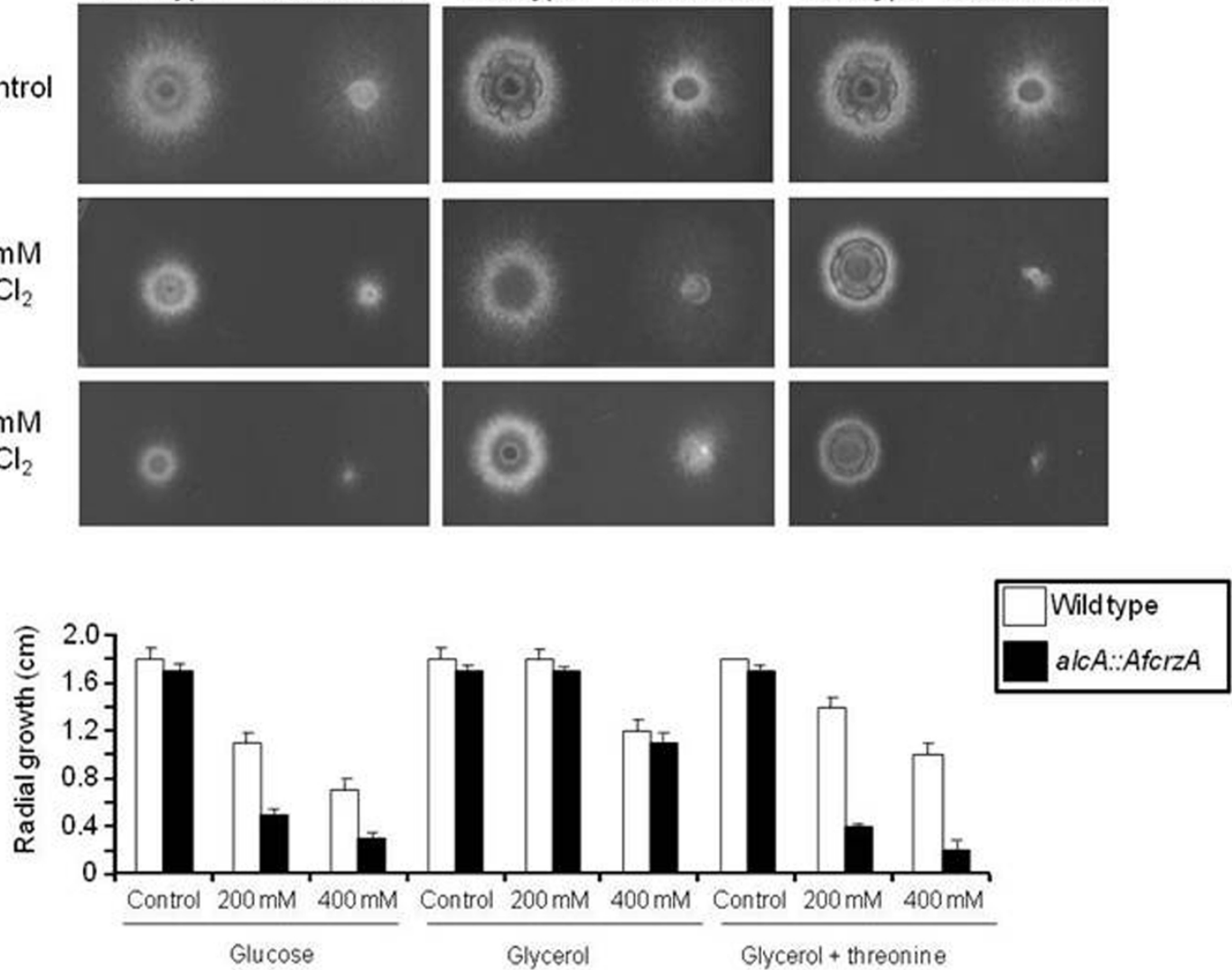

Figure 2 Growth phenotypes of $A$. fumigatus alcA::AfcrzA strains grown in the presence of different calcium concentrations. (A) Fold increase in AfcrzA mRNA levels after the growth of the wild type and alcA::AfcrzA strain either in MM+glycerol 2\%+ethanol $2 \%$ or $M M+g l y c e r o l$ $2 \%+$ threonine $100 \mathrm{mM}$ for 6 hours at $37^{\circ} \mathrm{C}$. The relative quantitation of AfcrzA and tubulin gene expression was determined by a standard curve (i.e., $C_{T}$-values plotted against logarithm of the DNA copy number). The results are the means \pm standard deviation of four sets of experiments. The values represent the number of times the genes are expressed compared to the corresponding wild type control strain (represented absolutely as 1.00). (B) A. fumigatus wild type and alcA::AfcrzA strains were grown for 48 hours at $37^{\circ} \mathrm{C}$ in $\mathrm{MM}+4 \%$ glucose, $\mathrm{MM}+2 \%$ glycerol, $\mathrm{MM}$ $+2 \%$ glycerol $+100 \mathrm{mM}$ threonine in the absence of presence of calcium chloride $200 \mathrm{mM}$ and $400 \mathrm{mM}$. The graph shows the radial growth (cm) of the strains under different growth conditions. The results are the means \pm standard deviation of four sets of experiments. 


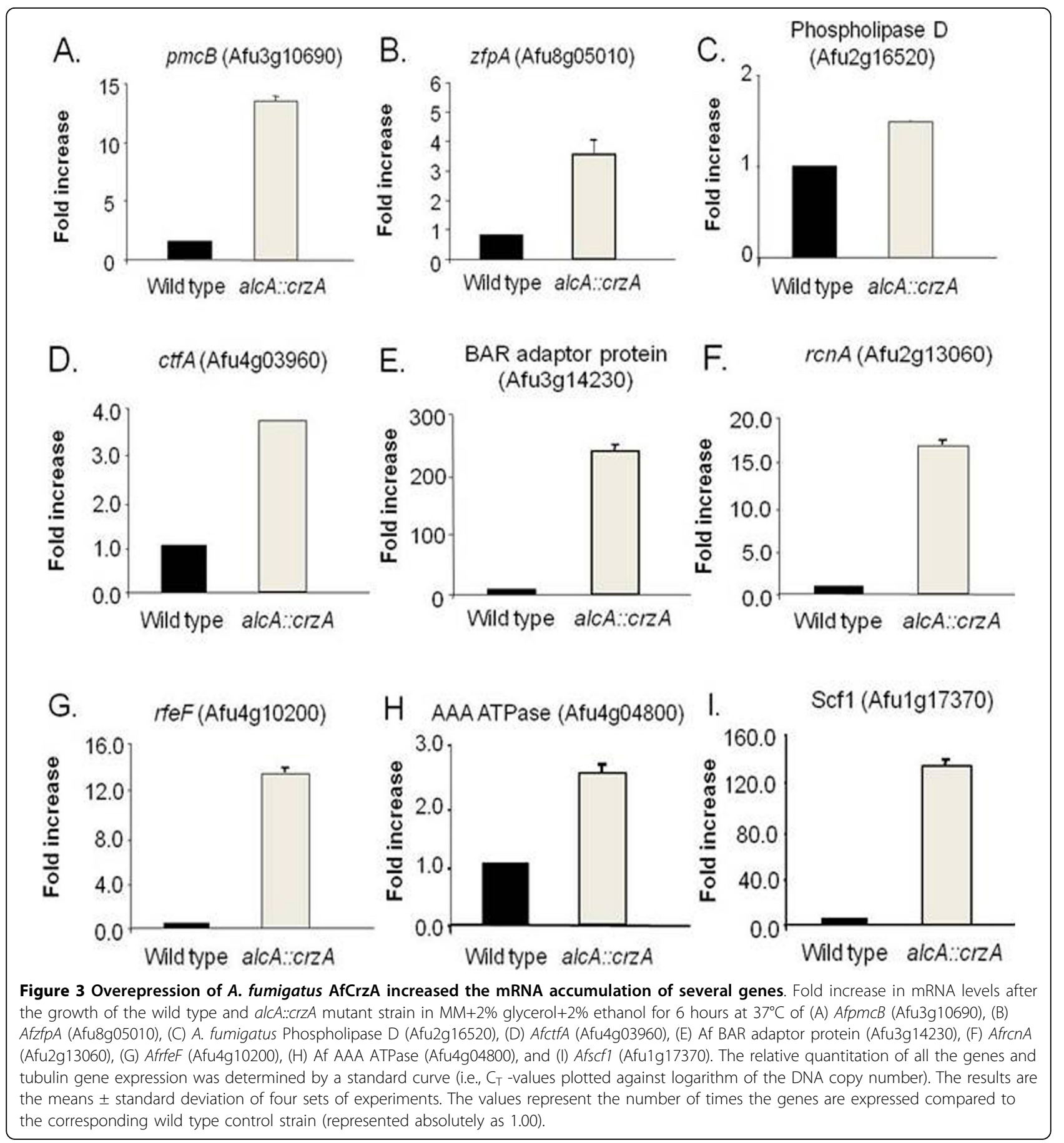

A. fumigatus AfRcnA belongs to a class of endogenous calcineurin regulators, calcipressins, a family of calcineurin-binding proteins, conserved from yeast to mammals [34,35]. A phylogenetic analysis was performed to determine the relationship of AfRcnA to calcipressin homologues in several different organisms (Additional file 3, Figure S1). The mechanism how this protein family functions still remains controversial. There are reports showing that calcipressins can both stimulate and inhibit the calcineurin pathway 34-36. Induction of S. cerevisiae RCN1-lacZ in response to calcium was completely blocked by addition of FK506 or by deletion of the genes encoding Tcn1p or calcineurin [33]. The $S$. cerevisiae RCN1 is also induced by calcium, repressed by calcium+FK506 and in the crz1 background [30]. Another member of this family, Cbp1, was identified in 
Cryptococcus neoformans, and is required for mating but not for growth at $37^{\circ} \mathrm{C}$ [37]. We have observed that AfrcnA mRNA accumulation upon calcium stress is dependent on both calcineurin and AfCrzA (Figure 1A). These results suggest that both $S$. cerevisiae and $A$. fumigatus RCAN homologues may be downstream targets of the calcineurin-dependent transcription factor. This fits a model where increased A. fumigatus AfRcnA regulation in response to calcineurin signaling is possibly a negative-feedback mechanism modulating calcineurin acitivity.

We constructed an $A$. nidulans alcA::AncrzA also by replacing the endogenous $A n c r z A$ promoter region homologously with the $A$. nidulans alc $A$ promoter. We investigate the genetic interactions between $\triangle A n c n a A$ and $\triangle A n c r z A$ mutations and a double mutant $\triangle A n c n a A$ $\triangle A n c r z A$ displays the same growth behavior than the $\triangle A n c n a A$ mutant indicating as expected that $A n c n a A$ is epistatic to AncrzA (data not shown).

\section{Molecular characterization of the Aspergilli calcipressin homologue}

To have more information about the function of some of the genes identified as more expressed in the A. fumigatus wild type and repressed in the $\triangle A f c r z A$, we inactivated the AfrcnA (Afu2g13060), AfrfeF (Afu4g10200), Af BAR adaptor protein (Afu3g14230), and A. fumigatus phospholipase D (Afu2g16520). Since calcium is involved in different kinds of stresses, such as oxidative stress and uncontrolled proliferation and survival [38-44], we decided to determine if several different culture conditions could affect the growth of these deletion strains. Except for $\triangle A \operatorname{frcn} A$, the deletion mutants showed comparable growth phenotypes to the wild type strain in the presence of the following agents or stressing situations: oxidizing agents and metals (paraquat, $t$ butyl hydroperoxide, zinc, iron, and chromium), calcium, cyclosporine A, DNA damaging agents (4-nitroquinoline oxide, hydroxyurea, camptothecin, and bleomycin), and temperature $\left(30,37\right.$, and $44^{\circ} \mathrm{C}$ ) (data not shown). However, $\triangle A$ frcnA growth was less sensitive to menadione $30 \mu \mathrm{M}$, hydrogen peroxide $2.5 \mathrm{mM}$, EGTA $25 \mathrm{mM}$, and $\mathrm{MnCl}_{2} 25 \mathrm{mM}$ (Figure 4B). We exposed both wild type and $\triangle A f r c n A$ strains for 200 $\mathrm{mM}$ calcium chloride for 10 minutes and measured the calcineurin activity in these strains (Figure 4C). In the wild type strain, there is about $50 \%$ increase in the calcineurin activity when the mycelia was exposed to calcium chloride $200 \mathrm{mM}$ for 10 minutes (Figure 4C). However, in the $\triangle A \operatorname{frcn} A$ mutant strain there is a significant increase in the calcineurin activity at 0 and 10 minutes in the presence of calcium chloride (Figure 4C). These results suggest that AfRenA has an inhibitory effect on calcineurin activity when $A$. fumigatus is exposed to high calcium concentrations.
We also investigated how the $\operatorname{Arcn} A$ deletion would affect the mRNA accumulation of the genes observed as modulated by AfCrzA (see Figure 1). Thus, we exposed both the wild type and $A f \Delta r c n A$ mutant strains to $\mathrm{CaCl}_{2}$ $200 \mathrm{mM}$ for 10 and 30 minutes and measured the mRNA accumulation of these genes (Figure 5). The absence of AfRcnA has a very heterogeneous influence on the mRNA accumulation of these genes. The AfrfeF (Afu4g10200) and Af AAA ATPase (Afu4g04800) genes have increased mRNA accumulation in the absence of AfrcnA when compared to the wild type strain (about 1.5- and 5.0-times and about the same and 5-times increased at 10 and 30 minutes, respectively; Figures $5 \mathrm{~A}$ and 5D). In contrast, the A. fumigatus phospholipase D (Afu2g16520) gene has lower mRNA accumulation of 3.6- and 5.0-times in the Af $\triangle r c n A$ mutant than the wild type strain (Figure $5 \mathrm{C}$ ). The mRNA accumulation of the Af BAR (Afu3g14230) and AfScf1 (Afu1g17370) genes is not affected by the absence of AfrcnA (Figures $5 \mathrm{~B}$ and $5 \mathrm{E})$. These data emphasize the complex influence of AfRenA on the calcineurin pathway, both stimulating and inhibiting genes in this pathway.

After several attempts, we were unable to obtain a completely functional $A$. fumigatus GFP::AfRcnA and an overexpression alcA:AfrcnA strains (data not shown). Thus, we decided to exploit the conserved features of $A$. nidulans calcineurin system [see [30]] and construct both an A. nidulans GFP and an alcA::AnrcnA strain. The $A$. nidulans AnRcnA homologue (AN6249.3) has about $71 \%$ identity and $82 \%$ (e-value $3 \mathrm{e}-94$ ) similarity with the A. fumigatus AnRcnA (see also Additional file 3 , Figure S1). Furthermore, to have a more detailed analysis of the $A$. nidulans AnRenA, we also constructed an A. nidulans $\triangle A n r c n A$ deletion strain (Figure 6A). We evaluated its phenotype by using the same strategies above outlined for the $A$. fumigatus $\triangle A$ frcnA. The $A$. nidulans $\triangle A n r c n A$ radial diameter is about $25 \%$ smaller than the wild type strain (Figure $6 \mathrm{~B}$ ). It is also more resistant to cyclosporine $A$ (observe both strains have the same radial diameter when grown in the presence of cyclosporine $\mathrm{A}$, however $A$. nidulans $\triangle A n r c n A$ is smaller than the wild type; Figure $6 \mathrm{~B})$. We have observed that the deletion of $A$. nidulans AnrcnA also confers more resistance to an oxidative stressing agent, paraquat at 4 $\mathrm{mM}$ (Figure 6B). Interestingly, $A$. nidulans showed about 3.5 times more mRNA accumulation of the $\operatorname{rcn} A$ gene when mycelia were exposed to $0.5 \mathrm{mM}$ menadione compared to mycelia not exposed to it (data not shown).

The first member identified from the calcipressin family, $R C A N 1$, was isolated from the hamster genome as a gene induced during transient adaptation to oxidative stress $[42,43]$. It was observed that resistance to oxidative stress and calcium stress increased as a function of $R C A N 1$ expression and decreased as its expression 


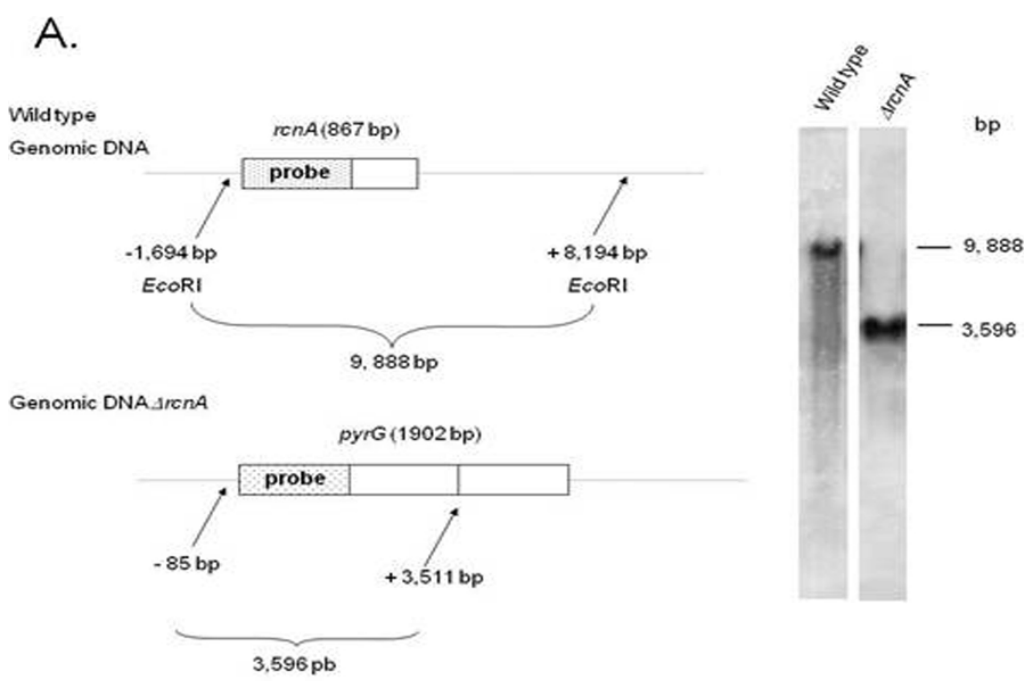

B.
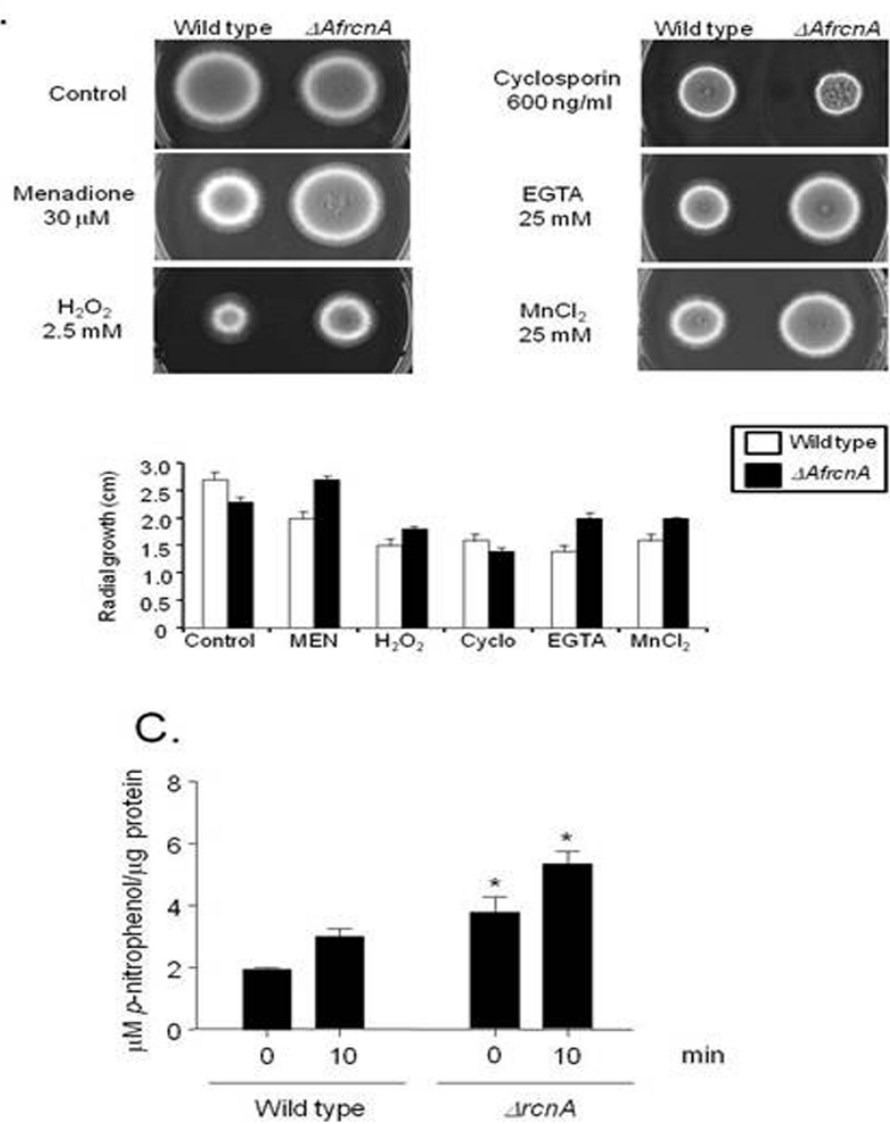

Figure 4 Molecular characterization of the A. fumigatus AfrcnA. (A) Schematic illustration of the rcnA deletion strategy. (A) Genomic DNA from both wild type and $\triangle A f r c n A$ strains was isolated and cleaved with the enzyme EcoRl; a 2.0-kb DNA fragment from the 5'-noncoding region was used as a hybridization probe. This fragment recognizes a single DNA band (about 9.8-kb) in the wild type strain and also a single DNA band (about 3.6-kb) in the $\triangle r c n A$ mutant as shown in the Southern blot analysis. (B) Wild type and $\triangle A$ frcnA mutant strains were grown for 72 hours at $37^{\circ} \mathrm{C}$ in complete medium in the absence or presence of menadione $30 \mu \mathrm{M}, \mathrm{H}_{2} \mathrm{O}_{2} 2.5 \mathrm{mM}$, cyclosporine A $600 \mathrm{ng} / \mathrm{ml}$, EGTA $25 \mathrm{mM}$, and $\mathrm{MnCl}_{2} 25 \mathrm{mM}$. The graph shows the radial growth $(\mathrm{cm})$ of the strains under different growth conditions. The results are the means \pm standard deviation of four sets of experiments. (C) Wild type and $\Delta \mathrm{rcnA}$ mutant strains were grown in $\mathrm{YG}$ medium for 16 hours at $37^{\circ} \mathrm{C}$ and then exposed to $200 \mathrm{mM} \mathrm{CaCl} 2$ for 10 minutes. Mycelial protein extracts were processed and calcineurin activity measured. Asterisks indicate the $\triangle r c n A$ samples are significantly different from the wild type strain $(p<0.05)$. 


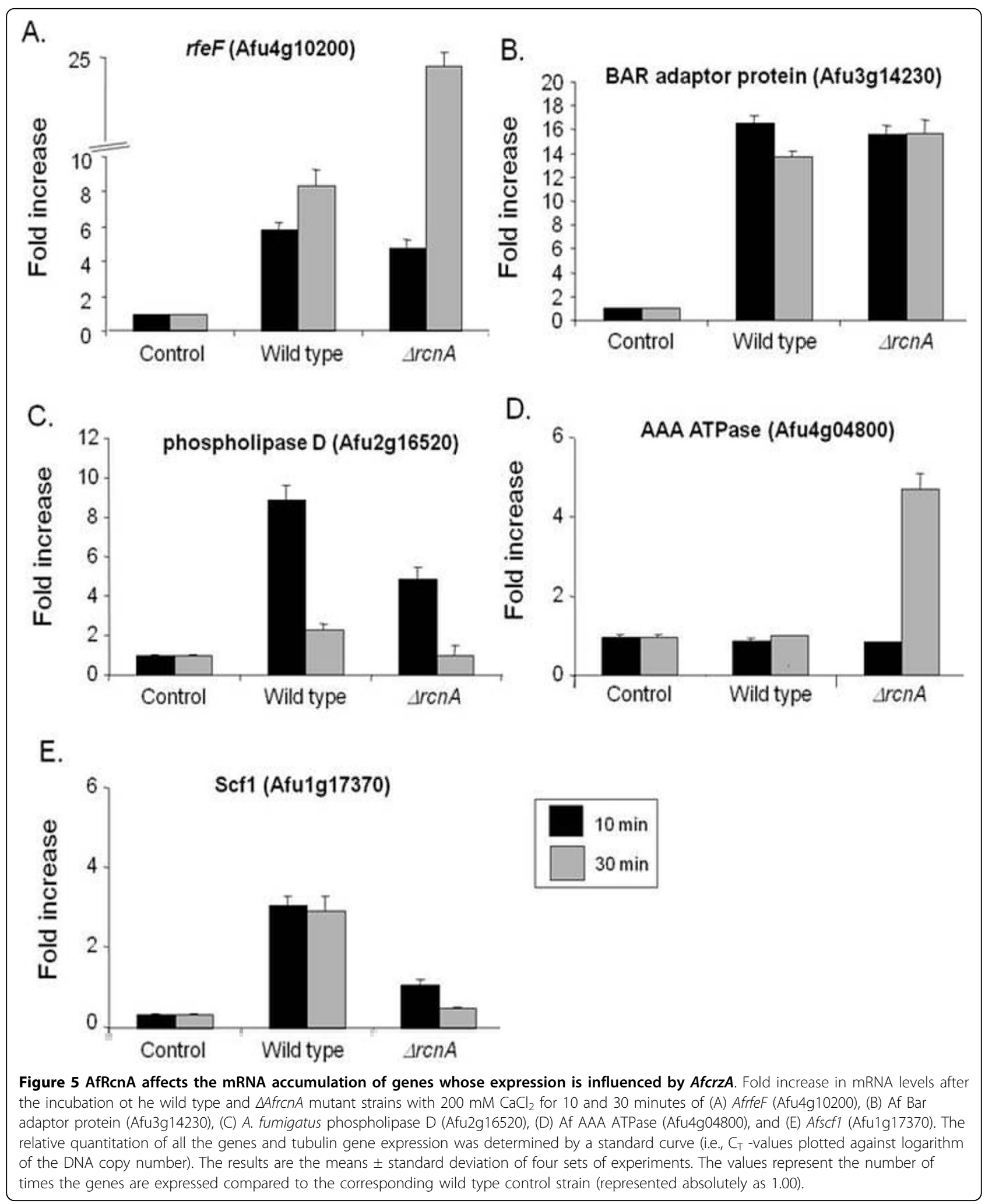




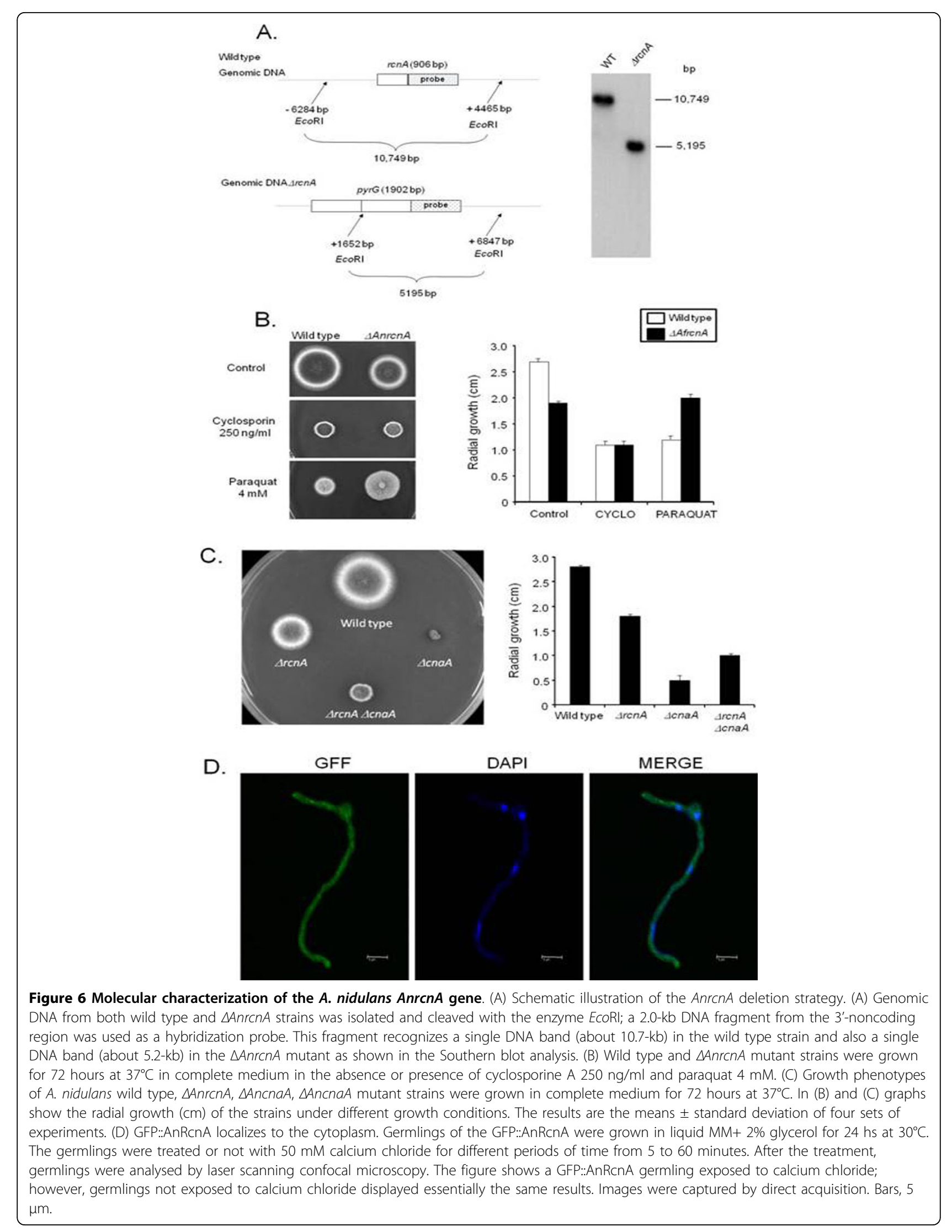


diminished [44]. Porta et al. [35] have shown that RCAN1 mRNA and protein expression are sensitive to oxidative stress in primary neurons, and that $R c a n 1^{-/-}$ neurons display an increased resistance to damage by hydrogen peroxide. Taken together, our results suggest that Aspergilli RcnA play a role in calcium and oxidative stress signaling.

Next step, we crossed the $A$. nidulans $\triangle A n r c n A$ strain with $\triangle A n c n a A$ strain (cnaA encodes the catalytic subunit of the calcineurin gene) [30]. The A. nidulans $\triangle A n r c n A$ mutation can partially suppress the $\triangle A n c n a A$ growth defect, suggesting a genetic interaction between AnRenA and AnCnaA (Figure 6C). To determine the AnRcnA cellular localization, we transformed a GFP:: AnRenA cassette into a wild type strain. Several transformants were obtained in which the plasmid had integrated homologously at the AnrcnA locus (data not shown). Thus, in these strains GFP::AnRcnA is the only source of protein and GFP::AnRcnA strains are completely functional, i.e., they displayed cyclosporine A/paraquat-sensitivity comparable to the wild type strain (data not shown). Figure 6D shows GFP::AnRcnA germlings that were grown for $24 \mathrm{hs}$ in $\mathrm{MM}+2 \%$ glycerol at $30^{\circ} \mathrm{C}$ and either incubated or not in the presence of calcium chloride $50 \mathrm{mM}$ or EGTA $25 \mathrm{mM}$ for 5 to 15 minutes. In all conditions, AnRcnA was mostly detected along the germling and did not accumulate in the nuclei (Figure $6 \mathrm{D}$ and data not shown). The same results were observed when glucose was used as a single carbon source (data not shown). These results show that AnRenA cellular localization is not affected by the cellular response to calcium chloride.

We overexpressed AnrcnA aiming to investigate genes that could be potentially regulated by the calcipressincalcineurin pathway. Accordingly, we constructed an $A$. nidulans overexpression AnrcnA strain by using the alcA promoter. We used real-time RT-PCR to test the mRNA levels of AnrcnA when the wild type and alcA:: AnrcnA strains were grown in the presence of either glucose or glycerol+ethanol as carbon sources (Figure 7A). The AnrcnA gene showed about the same mRNA accumulation when the wild type strain was grown either in the presence of glucose or glycerol+ethanol (Figures 7A). However, when the alcA::AnrcnA strain was grown in the presence of glycerol+ethanol, the AnrcnA gene had a mRNA accumulation of about 16.0 times when compared its growth in the presence of glucose (Figures 7A). Surprisingly, AnRcnA overexpression in liquid medium (for 16 hours at $37^{\circ} \mathrm{C}$ ) did not cause any growth inhibition in the presence of either calcium or cyclosporine (data not shown). AnRenA overexpression (for 16 hours at $37^{\circ} \mathrm{C}$ ) also had no effect on the $\triangle A n c n a A$ phenotype in liquid medium (data not shown). Next, we observed the effects of overexpressing
AnRcnA on calcineurin activity. Interestingly, calcineurin activity is dramatically increased when the wild type strain was grown in the presence of ethanol (Figure $7 \mathrm{~B})$. In the alcA::AnrcnA strain, calcineurin activity was reduced about $50 \%$ (Figure 7B), what it is again consistent with a role for Aspergilli RcnAs in the inhibition of calcineurin activity. Both strains display the same calcineurin activity when grown in the presence of glucose (Figure 7B). Assuming an inhibitory role for AnRcnA on the calcineurin activity, it should be expected an increase in the calcineurin activity for the alcA::AnrcnA grown in the presence of glucose. However, the lack of reduction in the calcineurin activity is possibly due to the fact that the $r c n A$ mRNA accumulation was not completely abolished in the alcA::AnrcnA grown in the presence of glucose (Figure 7A). Overexpression of the yeast protein $\operatorname{Rcn} 1 \mathrm{p}$ or the human homologues also inhibited the activation of the transcription factor Crz1p and the inhibition of the $\mathrm{H}^{+} / \mathrm{Ca}^{2+}$ exchanger Vcx1p [33].

We investigated the effects of AnRcnA overexpression on the mRNA accumulation of the calcium transporters $p m c A$ (AN1189.3) and $p m c B$ (AN4920.3), two A. nidulans $P M C 1$ homologues. Low and about similar $p m c A$ and $p m c B$ mRNA accumulation were seen when the wild type and the alcA::AnrcnA mutant strains were grown in the presence of glucose (Figure $7 C$ ). In contrast, $p m c A$ and $p m c B$ levels were about 16 and 5 times higher the alcA::AnrcnA strain than in the wild type when both strains were grown in the presence of glycerol+ethanol (Figure 7C). These results strongly suggest that AnRcnA can directly or indirectly influence the $p m c A$ and $p m c B$ mRNA accumulation. Thus, it is possible RcnA has both stimulatory and inhibitory activity depending on the calcineurin pathway activation by calcium stress.

Taken together, these results strongly suggest that: (i) $r c n A$ genes are involved in the oxidative stress and calcium stress in Aspergilli, (ii) both AncnaA and AnrcnA genes showed genetic interactions, and (iii) RcnA can modulate calcineurin activity and the mRNA accumulation of genes encoding calcium transporters. What is the nature of the interaction between Aspergilli CnaA and RcnA? These interactions could mean protein-protein interactions, and considering that calcipressin homologues from other species were already shown to interact with calcineurin 35,45 , we investigated the possibility of AfRenA to bind AfCnaA by using yeast twohybrid analysis. Our results have not revealed any even weak interaction between these two proteins (data not shown), suggesting that the basis for the interaction is either not related to protein-protein interaction or alternatively there are other proteins or conditions that mediate this interactions that cannot be completely recapitulated by using yeast two-hybrid assays. The 


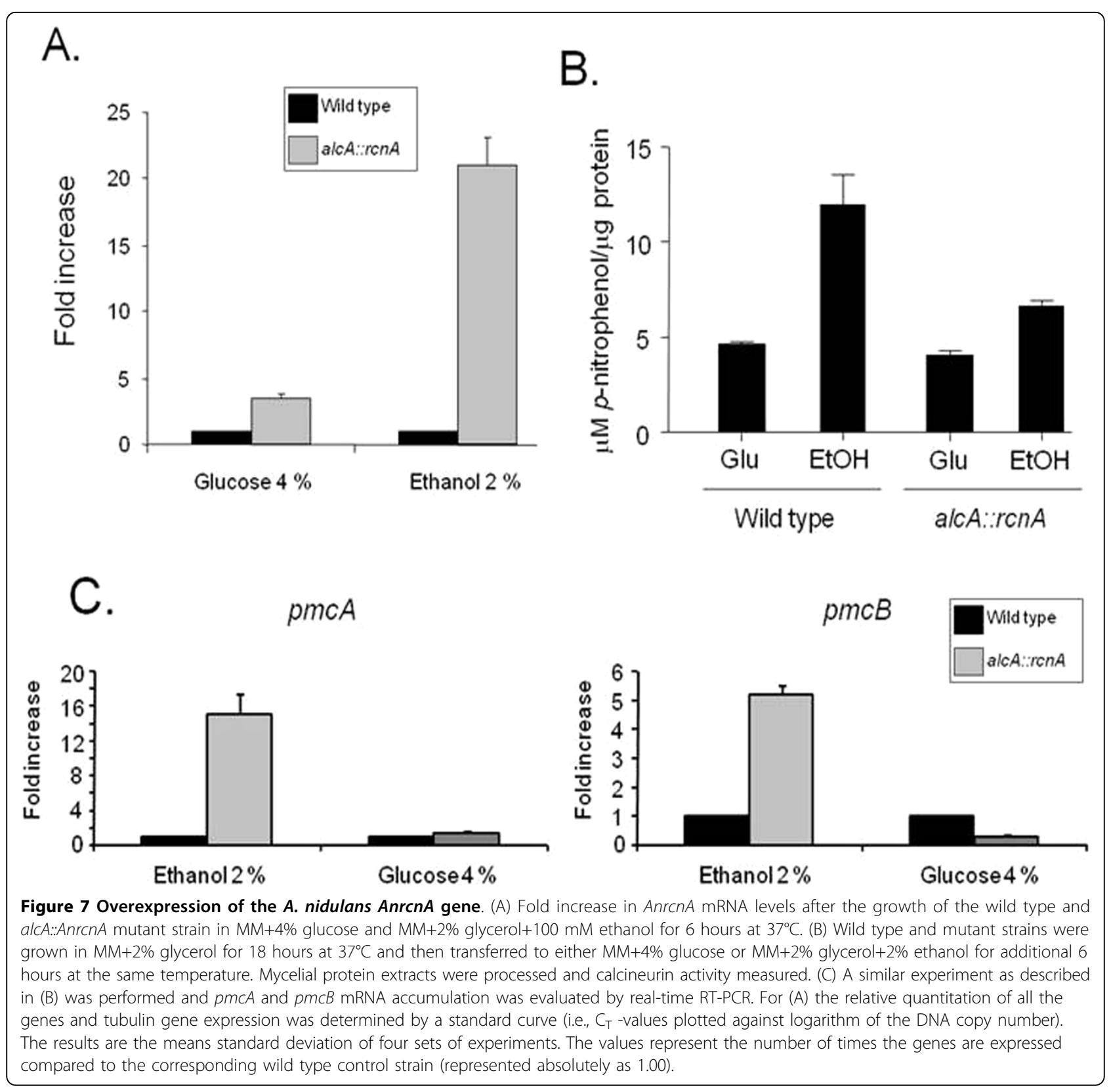

$\triangle A n r c n A$ mutation suppresses the $\triangle A n c n a A$ mutation and suppression of a null allele is expected to be due to downstream mutations that activate the pathway independent of the original (suppressed) gene product [45]. This suppression is essentially visible in terms of the recovery of the colonial growth and increase in the radial diameter of the double mutant (see Figure $5 \mathrm{C}$ ). Considering the dramatic morphological phenotype of $\triangle A n c n a A$ strain, it is possible that besides controlling calcineurin activity, AnRcnA is also involved in Aspergillus development. Involvement of calcipressins in development has been previously reported for the Drosophila melanogaster sarah mutants [46]. Eggs laid by sarah mutant females arrest in anaphase of meiosis I and fail to fully polyadenylate and translate bicoid mRNA. Furthermore, sarah mutant eggs show elevated cyclin B levels, indicating a failure to inactivate $\mathrm{M}$-phase promoting factor (MPF). Taken together, these results demonstrate that calcium signaling is involved in Drosophila egg activation. It remains to be determined the further involvement of AnRcnA in A. nidulans development.

During the writing of this paper, a complementary study reporting the construction of the $\triangle A$ frcnA mutant in the A. fumigatus strain AF293 was published (named CbpA) [47]. These authors observed that deletion of the $\operatorname{cbpA}$ gene resulted in reduced hyphal growth and 
limited attenuated virulence. Different from our results, they also observed that the $\triangle c b p A$ strain showed increased calcium tolerance compared to the wild-type strain. Some differences between ours and their results can be credited to A. fumigatus strain differences. However, it is interesting to emphasize the fact that both Aspergilli showed some differences in the susceptibilities to manganese and EGTA (A. fumigatus) and cyclosporine A ( $A$. nidulans). In contrast, those authors have shown that the A. fumigatus AF293 $\triangle c b p A$ and wildtype strains displayed an equal sensitivity to the oxidants menadione and hydrogen peroxide, and were also not able to demonstrate a direct protein-protein interaction between A. fumigatus CbpA and AfCnaA [47].

\section{Conclusion}

We have performed a transcriptional profiling analysis of the A. fumigatus $\triangle A f c r z A$ mutant strain exposed to calcium stress. This provided an excellent opportunity to identify genes and pathways that are under the influence of AfCrzA. We validated the relationship between AfCrzA and these selected genes by using deletion analysis and by checking through real-time RT-PCR the mRNA accumulation of these genes expressed either in the $\triangle A f c r z A$ or overexpression strains. AfRcnA, one of these selected genes, encodes a modulator of calcineurin activity. Recently, we demonstrated that contrary to previous findings, the gene encoding the $A$. nidulans calcineurin catalytic subunit homologue, AncnaA, is not essential and that the AncnaA deletion mutant shares the morphological phenotypes observed in the corresponding $A$. fumigatus mutant, $\Delta$ calA [30]. Thus, we decided once more to exploit the conserved features of A. nidulans calcineurin system and concomitantly with A. fumigatus AfrcnA molecular analysis, we investigated the A. nidulans AnRcnA homologue. AnRenA showed to interact genetically with AnCnaA and be responsible for modulating the calcineurin activity and mRNA accumulation of genes encoding calcium transporters.

In summary, our work opens exciting new avenues for research into environmental sensing and nutrient acquisition mediated by the calcineurin-CrzA pathway in this important human pathogen.

\section{Methods}

\section{Strains and media methods}

A. fumigatus strains used in this study are CEA17 (pyrG-), CEA17-80 (wild type), $\triangle$ calA [9], FMS5 ( $\triangle c r z A::$ pyrG) [16], ALCCRZA (alcA::crzA), and RCNA ( $\triangle r c n A)$. A. nidulans strains used are GR5 (pyroA4 pyrG89; $w A 3$ ), TNO2a3 (pyroA4 pyrG8 $\triangle n K U a:: a r g B$ ) [49], CNA1 ( $\triangle$ cnaA::pyroA; pyroA4 pyrG89; wA3) [16], ALCRZA1 (pyroA4, alcA::gfp::crzA), RCNA1 (pyroA4, $\Delta r c n A:: p y r G)$, and ALCARCNA (pyroA4, alcA::gfp::rcnA). Media were of two basic types. A complete medium with three variants: YAG ( $2 \%$ glucose, $0.5 \%$ yeast extract, $2 \%$ agar, trace elements), YUU (YAG supplemented with $1.2 \mathrm{~g} / \mathrm{l}$ each of uracil and uridine) and liquid YG or YG + UU medium of the same compositions (but without agar). A modified minimal medium (MM: $1 \%$ glucose, original high nitrate salts, trace elements, $2 \%$ agar, $\mathrm{pH} 6.5$ ) was also used. Trace elements, vitamins, and nitrate salts are described by Kafer [48]. Expression of tagged genes under the control of alcA promoter was regulated by carbon source: repression on glucose $4 \%(w / v)$, derepression on glycerol and induction on ethanol or threonine. Therefore, MM-G and MM-E (or MM-T) were identical to $M M$, except that glycerol $(2 \% \mathrm{v} / \mathrm{v})$ and/or ethanol $(2 \% \mathrm{v} / \mathrm{v}$ for liquid medium) or threonine (100 $\mathrm{mM}$ for solid medium) were used, respectively, in place of glucose as the sole carbon source. Strains were grown at $37^{\circ} \mathrm{C}$ unless indicated otherwise. Cyclosporine $\mathrm{A}$ (CsA) used in the experiments throughout the manuscript is from Neoral ${ }^{\mathrm{Tm}}$ Sandimmun (Novartis). Standard genetic techniques for $A$. nidulans were used for all strain constructions [49].

\section{RNA isolation}

For the microarray experiments, $1.0 \times 10^{9}$ conidia of $A$. fumigatus wild type and $\triangle c r z A$ strains were used to inoculate $400 \mathrm{ml}$ liquid cultures (YG) in $1000 \mathrm{ml}$ erlenmeyer flasks that were incubated in a reciprocal shaker (250 rpm) at $37^{\circ} \mathrm{C}$ for 16 hours. After this period, the germlings were harvested by filtration and transferred to a fresh YG medium plus $200 \mathrm{mM}$ of $\mathrm{CaCl}_{2}$ for either 10 or 30 minutes. Again, after this period, the germlings were harvested by centrifugation or filtration immediately frozen in liquid nitrogen. For total RNA isolation, the germlings were disrupted by grinding in liquid nitrogen with pestle and mortar and total RNA was extracted with Trizol reagent (Invitrogen, USA). Ten micrograms of RNA from each treatment were then fractionated in 2.2 $\mathrm{M}$ formaldehyde, $1.2 \% \mathrm{w} / \mathrm{v}$ agarose gel, stained with ethidium bromide, and then visualized with UV-light. The presence of intact $25 \mathrm{~S}$ and $17 \mathrm{~S}$ ribosomal RNA bands was used as a criterion to assess the integrity of the RNA. RNAse free DNAse I treatment for the realtime RT-PCR experiments was carried out as previously described [50].

\section{Assay for calcineurin activity}

Cytoplasmic extracts were prepared by homogenizing the mycelia using liquid nitrogen in a buffer containing $50 \mathrm{mM}$ Tris- $\mathrm{HCl}, \mathrm{pH7} .4,1 \mathrm{mM}$ EGTA, 0.2\% Triton X$100,1 \mathrm{mM}$ benzamidine, and $10 \mathrm{~g} / \mathrm{ml}$ each of leupeptin, pepstatin and aprotinine. The homogenates were clarified by centrifugation at $10,000 \times \mathrm{g}$ for $10 \mathrm{~min}$ at $4^{\circ} \mathrm{C}$ and then at $20,800 \times \mathrm{g}$ for $60 \mathrm{~min}$ at $4^{\circ} \mathrm{C}$. Protein content in the extracts was determined by the method of Bradford [51] and then used for calcineurin activity 
assays. Calcineurin activity in the cytoplasmic extracts was assayed according to the method of Wang and Pallen [52], with minor modifications, by determining calmodulin-dependent protein phosphatase activity in the absence or in the presence of the inhibitor CsA ( $5 \mathrm{mM})$. CsA is an immunosuppressant that targets calcineurin by forming a molecular complex with cytosolic protein cyclophilin of immunocompetent lymphocytes, especially T-lymphocytes. This complex of CsA and cyclophylin inhibits its phosphatase activity. Assays were performed in a reaction mixture (100- 1 volume) containing $25 \mathrm{mM}$ Tris (pH 7.2), $25 \mathrm{mM}$ MES (pH 7.0), $5 \mathrm{mM} p$-nitrophenyl phosphate, followed by incubation at $30^{\circ} \mathrm{C}$ for 10 $\mathrm{min}$, and terminated by the addition of $10 \mathrm{l}$ of $13 \% \mathrm{w} /$ v) $\mathrm{KH} 2 \mathrm{PO} 4$. The absorbance of the samples was measured immediately at $405 \mathrm{nM}$. The difference between the amounts of $p$-nitrophenol released in the absence and the presence of ciclosporin represented the phosphatase activity mediated by calcineurin. One unit of enzyme activity is defined as nmol of $p$-nitrophenol released from $p$-nitrophenyl phosphate. $\mathrm{min}^{-1}$. mg protein $^{-1}$.

\section{Gene Expression Methods}

We have used the A. fumigatus oligonucleotide slides version 2 for microarray hybridizations (for details see http://pfgrc.jcvi.org/index.php/microarray/array_description/aspergillus_fumigatus/version2.html). The RNA samples extracted, as described above, were further purified with the RNA easy kit (Qiagen, Germany) and directly labelled by incorporation of Cy3- or Cy5-dUTP (GE Health Care). The resulting data was averaged from duplicate genes on each array, from dye-swap hybridizations for each experiment, and from two biological replicates, taking a total of 8 intensity data points for each gene. Differentially expressed genes at the $95 \%$ confidence level were determined using intensity-dependent $\mathrm{Z}$-scores (with $\mathrm{Z}=1.96$ ) as implemented in MIDAS and the union of all genes identified at each time point were considered significant in this experiment. The resulting data were organized and visualized based on similar expression vectors in genes using Euclidean distance and hierarchical clustering with average linkage clustering method to view the whole data set and k-means to group the genes in 60 clusters with TIGR MEV (multi experiment viewer), also available at http://www.jcvi.org/ $\mathrm{cms} /$ research/software. All the hybridization conditions and microarray data analysis were performed as previously described by Malavazi et al. [53]. When RT-PCR was used to assess the reliability of the microarray hybridizations germlings were exposed to a novel growth curve (new RNA samples, not stocks of the original RNA used in the array experiment).

\section{Real-time RT PCR reactions}

All the PCR and RT-PCR reactions were performed using an ABI 7500 Fast Real-Time PCR System (Applied Biosystems, USA). Taq- Man $^{\text {Tw }}$ Universal PCR Master Mix kit (Applied Biosystems, USA) was used for PCR reactions. The reactions and calculations were performed according to Semighini et al. [49]. The primers and Lux ${ }^{\mathrm{mm}}$ fluorescent probes (Invitrogen, USA) used in this work are described in Additional file 4, Table S3.

\section{Staining and microscopy}

For cell imaging of RcnA fused to GFP, conidiospores were grown in glass-bottom dishes (Mattek Corporation, USA) in $2 \mathrm{ml}$ of $\mathrm{MM}+2 \%$ glycerol for 24 hours at $30^{\circ} \mathrm{C}$. All the confocal images were analysed using the Leica TCS SP5 laser scanning confocal microscope (Leica Microsystems, Heidelberg, Germany) (Laboratory of Confocal Microscopy, FMRP-USP, Brazil) using 63× magnification water immersion objective lens using laser lines $488 \mathrm{~nm}$ for GFP and $405 \mathrm{~nm}$ for DAPI. Images were captured by direct acquisition with the Leica LAS AF software (Leica Microsystems) and additional processing was carried out using Adobe Photoshop 7.0 (Adobe Systems Incorporated, CA).

\section{DNA manipulations and construction of the Aspergilli conditional mutants}

DNA manipulations were according to Sambrook and Russell [54]. All PCR reactions were performed using Platinum Taq DNA Polimerase High Fidelity (Invitrogen). For the DNA-mediated transformation, the deletion cassettes were constructed by "in vivo" recombination in $S$. cerevisiae as previously described by Colot et al. [55]. About 2.0-kb regions on either side of the ORFs were selected for primer design. For the construction of the A. fumigatus rcnA deletion, the primers calp-Afu P1 and calp-Afu P2 were used to amplify the 5'-UTR flanking region of the targeted ORF. The primers calp-Afu P3 and calp-Afu P4 were used to amplify the 3'-UTR ORF flanking region. For the construction of the A. nidulans rcnA deletion, the primers calp-Ani P1 and calp-Ani P2 were used to amplify the 5'-UTR flanking region of the targeted ORF. The primers calpAni P3 and calp-Ani P4 were used to amplify the 3'UTR ORF flanking region. Both fragments 5- and 3UTR were PCR-amplified from genomic DNA using as templates the A4 strain for A. nidulans and AFU293 for A. fumigatus cassettes. The pyrG used in the Aspergilli cassettes for generating both deletion strains was used as marker for auxotrophy and were amplified (by using primers pyrG $\mathrm{Fw}$ and pyrG $\mathrm{Rw}$ ) from pCDA21 plasmid [56].

Cassettes generation was achieved by transforming each fragment for each construction along with the plasmid pRS426 BamHI/EcoRI cut in the in S. cerevisiae strain SC9421 by the lithium acetate method [57]. The 
DNA of the yeast transformants was extracted by the method described by Goldman et al. [58], dialysed and transformed by electroporation in Escherichia coli strain DH10B to rescue the pRS426 plasmid harboring the cassettes. The cassettes were PCR-amplified from these plasmids and used for transformation of Aspergilli according to the procedure of Osmani et al. [59]. Transformants were scored for their ability to grow on minimal medium. PCR or Southern blot analyses were used throughout of the manuscript to demonstrate that the transformation cassettes had integrated homologously at the targeted $A$. fumigatus or $A$. nidulans loci.

The $A$. fumigatus alcA::AfcrzA and $A$. nidulans alcA:: $A n c r z A$ constructions were performed by amplifying by PCR 5'-end fragments (for $A$. fumigatus, 1084-bp from the start codon of the ORF with the primers Afcrz1 AscI: 5'-GGCGCGCCAATGGCTTCACAGGAGATGTTCC-3' and Afcrz1 PacI: 5'-CCTTAATTAAGCACATTGGGCATCATTTCCTGTCC-3'; and for $A$. nidulans, $1068 \mathrm{bp}$ from the start codon of the ORF with the primers AncrzA AscI 5'-GGCGCGCCAATGGATCCTCAAGATACGCTGCAGG-3' and AncrzA PacI 5'-CCTTAATTAACATCTGTGACGCTTGCCCGATATC-3'), digesting them with PacI and AscI, and cloning them in the corresponing PacI and $A s c I$ restriction sites of the pMCB17-apx plasmid. The fragment of the ORF is under the control of the A. nidulans alcA promoter and after homologous integration the translation produces an N-terminal fusion protein. A. fumigatus and $A$. nidulans pyrG $G^{-}$strains were transformed with the corresponding vectors $\mathrm{pMCB} 17$-apx-crzA and after homologous recombination the alcA::gfp::crzA construction and a truncated $c r z A$ non-coding gene were generated. All the transformants were confirmed by PCR using specific primers.

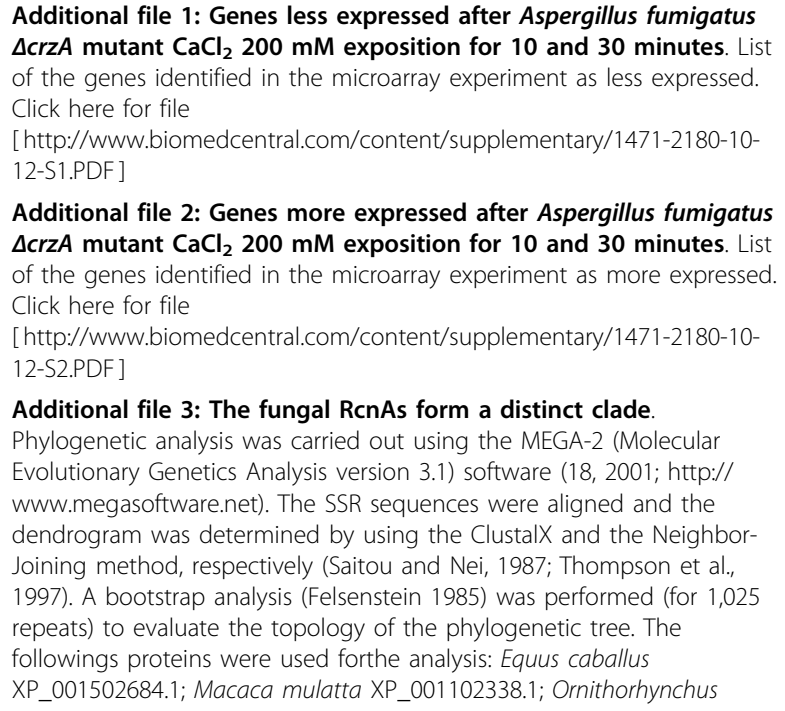

anatinus XP_001511608.1; Gallus gallus XP_420062.2; Monodelphis domestica XP_001363457.1; Homo sapiens NP_005813.2; Bos taurus NP_001015632.1; Rattus norvegicus NP_001012764.1; Tetraodon nigroviridis gi|47230037; Xenopus tropicalis gi|89272039|; Xenopus laevis NP_001080661.1; Canis familiaris. XP_858285.1; Mus musculus NP_062339.2; Gorilla gorilla gi|120975069|; Macaca fascicularis gi| 90077144|; Danio rerio XP_001922378.1; Apis mellifera XP_396593.2; Nasonia vitripennis XP_001603743.1; Tribolium castaneum XP_969761.1; Drosophila mojavensis gi|193916784|; Drosophila grimshawi gi|193893692|; Drosophila pseudoobscura XP_001359704.1; Drosophila erecta gi| 190651857|; Drosophila melañogaster NP_524378.1; Brugia malayi XP_001895925.1; Malassezia globosa XP_001730302.1; Ustilago maydis XP_756572.1; Cryptococcus neoformans XP_567126.1; Laccaria bicolor XP_001878504.1; Coprinopsis cinerea XP_001839847.1; Yarrowia lipolytica XP_503761.1; Neosartorya fischeri XP_001260765.1; Aspergillus fumigatus Af293 XP_755638.1; Aspergillus clavatus XP_001275581.1; Aspergillus terreus XP_001208640.1; Aspergillus oryzae XP_001821801.1; Aspergillus niger XP_001399317.1; Aspergillus nidulans XP_663853.1; Coccidioides immitis XP_001245666.1; Ajellomyces capsulatus XP_001541658.1; Phaeosphaeria nodorum XP_001797869.1; Pyrenophora tritici-repentis XP_001935909.1; Botryotinia fuckeliana XP_001554496.1; Sclerotinia sclerotiorum XP_001593917.1; Chaetomium globosum XP_001228347.1; Neurospora crassa XP_956953.1; Magnaporthe grisea XP_360675.1; Gibberella zeae XP_381626.1; Podospora anserina XP_001909744.1. References: Felsenstein J (1985); Confidence limits on phylogenies: an approach using the bootstrap. Evolution 39: 783-791. Saitou N, Nei M (1987); The neighborjoining method: a new method for reconstructing phylogenetic trees. Mol Biol Evol 4: 406-425.Thompson JD, Gibson TJ, Plewniak F, Jeanmougin F, Higgins DG (1997); The ClustalX windows interface: flexible strategies for multiple sequence alignment aided by quality analysis tools. Nucleic Acids Res. 24: 4876-4882.

Click here for file

[http://www.biomedcentral.com/content/supplementary/1471-2180-1012-S3.JPEG]

Additional file 4: Primers used in this work. List of primers used for PCRs and real time PCRs.

Click here for file

[http://www.biomedcentral.com/content/supplementary/1471-2180-1012-S4.PDF ]

\section{Acknowledgements}

We would like to thank the Laboratories of Confocal Microscopy and Electronic Microscopy from the Faculdade de Medicina de Ribeirão Preto, Universidade de São Paulo, Brazil, for the use of the confocal microscope, and the four anonymous reviewers for their suggestions. This research was supported by the Fundação de Amparo à Pesquisa do Estado de São Paulo (FAPESP), Conselho Nacional de Desenvolvimento Científico e Tecnológico (CNPq), Brazil, and John Simon Guggenheim Memorial Foundation, USA.

\section{Author details}

${ }^{1}$ Centro de Ciência e Tecnologia do Bioetanol and Faculdade de Ciências Farmacêuticas de Ribeirão Preto Universidade de São Paulo, São Paulo, Ribeirão Preto, 14040-903, Brazil. 'Faculdade de Filosofia, Ciências e Letras de Ribeirão Preto, Universidade de São Paulo, São Paulo, Ribeirão Preto, 14040903, Brazil. ²Departamento de Genética e Evolução, Centro de Ciências Biológicas e da Saúde (CCBS), Universidade Federal de São Carlos, São Paulo, São Carlos, 13565-905, Brazil. Departamento de Microbiología Molecular, Centro de Investigaciones Biológicas CSIC, Ramiro de Maeztu, 9. Madrid 28040, Spain.

\section{Authors' contributions}

FMS carried out microarray hybridization experiments and analysis, construction of A. fumigatus deletion and overexpression strains, and realtime RT-PCR experiments. IM performed the yeast two-hybrid experiments, the construction of alcA::rcnA strain, the GFP microscopy, characterized the RcnA deletion and overexpression strains. MS helped and performed the real-time RT-PCR and fungal transformation experiments. LASB contributed with the bioinformatics analysis. MESF, TMD, EE and MHSG contributed to 
design of the experiments and discussion of the results. GHG wrote the manuscript and supervised all the work. All authors read and approved the final manuscript

Received: 30 March 2009

Accepted: 15 January 2010 Published: 15 January 2010

\section{References}

1. Fox DS, Heitman J: Good fungi gone bad: the corruption of calcineurin. Bioessays 2002, 24:894-903.

2. Cyert MS: Calcineurin signaling in Saccharomyces cerevisiae: how yeast go crazy in response to stress. Biochem Biophys Res Commun 2003, 311:1143-1150.

3. Steinbach WJ, Reedy JL, Cramer RA, Perfect JR Jr, Heitman J: Harnessing calcineurin as a novel anti-infective agent against invasive fungal infections. Nat Rev Microbiol 2007, 5:418-430.

4. Stie J, Fox D: Calcineurin regulation in fungi and beyond. Eukaryot Cell 2008, 7:177-186.

5. Cyert MS: Genetic analysis of calmodulin and its targets in Saccharomyces cerevisiae. Annu Rev Genet 2001, 35:647-672.

6. Cruz MC, Fox DS, Heitman J: Calcineurin is required for hyphal elongation during mating and haploid fruiting in Cryptococcus neoformans. EMBO J 2001, 20:1020-1032.

7. Kontonyannis DP, Lewis RE, Osherov N, Albert ND, May GS: Combination of caspofungin with inhibitors of the calcineurin pathway attenuates growth in vitro in Aspergillus species. J Antimicrob Chemother 2003, 51:313-316.

8. Steinbach WJ, Singh N, Miller JL, Benjamin DK Jr, Schell WA, Heitman J, Perfect JR: In vitro interactions between antifungals and immunosuppressants against Aspergillus fumigatus isolates from transplant and nontransplant patients. Antimicrob Agents Chemother 2004 , 48:4922-4925.

9. da Silva Ferreira ME, Heinekamp $T$, Härt A, Brakhage AA, Semighini CP, Harris SD, Savoldi M, de Gouvêa PF, de Souza Goldman MH, Goldman GH: Functional characterization of the Aspergillus fumigatus calcineurin. Fungal Genet Biol 2007, 44:219-230.

10. Odom A, Muir S, Lim E, Toffaletti DL, Perfect J, Heitman J: Calcineurin is required for virulence of Cryptococcus neoformans. EMBO J 1997, 16:25762589.

11. Cruz MC, Sia RA, Olson M, Cox GM, Heitman J: Comparison of the roles of calcineurin in physiology and virulence in serotype $D$ and serotype $A$ strains of Cryptococcus neoformans. Infect Immun 2000, 68:982-985.

12. Cruz MC, Goldstein AL, Blankenship JR, Del Poeta M, Davis D, Cardenas ME, Perfect JR, McCusker JH, Heitman J: Calcineurin is essential for survival during membrane stress in Candida albicans. EMBO J 2002, 21:546-559.

13. Fox DS, Cruz MC, Sia RA, Ke H, Cox GM, Cardenas ME, Heitman J: Calcineurin regulatory subunit is essential for virulence and mediates interactions with FKBP12-FK506 in Cryptococcus neoformans. Mol Microbiol 2001, 39:835-849.

14. Sanglard D, Ischer F, Marchetti O, Entenza J, Bille J: Calcineurin A of Candida albicans: involvement in antifungal tolerance cell morphogenesis and virulence. Mol Microbiol 2003, 48:959-976.

15. Blankenship JR, Wormley FL, Boyce MK, Schell WA, Filler SG, Perfect JR, Heitman J: Calcineurin is essential for Candida albicans survival in serum and virulence. Eukaryot Cell 2003, 2:422-430.

16. Soriani FM, Malavazi I, da Silva Ferreira ME, Savoldi M, Von Zeska Kress MR, de Souza Goldman MH, Loss O, Bignell E, Goldman GH: Functional characterization of the Aspergillus fumigatus CRZ1 homologue, CrzA. Mol Microbiol 2008, 67:1274-1291.

17. Stathopoulos-Gerontides A, Guo JJ, Cyert MS: Yeast calcineurin regulates nuclear localization of the Crz1p transcription factor through dephosphorylation. Genes Dev 1999, 13:798-803.

18. Karababa M, Valentino E, Pardini G, Coste AT, Bille J, Sanglard D: CRZ1, a target of the calcineurin pathway in Candida albicans. Mol Microbiol 2006, 59:1429-1451.

19. Stathopoulos AM, Cyert MS: Calcineurin acts through the CRZ1/TCN1encoded transcription factor to regulate gene expression in yeast. Genes Dev 1997, 11:3432-3445.

20. Zakrzewska A, Boorsma A, Brul S, Hellinngwerf KJ, Klis FM: Transcriptional response of Saccharomyces cerevisiae to the plasma membraneperturbing compound chitosan. Eukariot Cell 2005, 4:703-715.
21. Matheos DP, Kingsbury TJ, Ahsan US, Cunningham KW: Tcn1p/Crz1p, a calcineurin-dependent transcription factor that differentially regulates gene expression in Saccharomyces cerevisiae. Genes Dev 1997, 11:34453458 .

22. Hirayama S, Sugiura R, Lu Y, Maeda T, Kawagishi K, Yokoyama M, Tohda H, Giga-Hama Y, Shuntoh $\mathrm{H}$, Kuno T: Zinc finger protein Prz1 regulates $\mathrm{Ca}^{+2}$ but not $\mathrm{Cl}^{-}$homeostasis in fission yeast. J Biol Chem 2003, 20:1807818084.

23. Onyewu C, Wormley FL Jr, Perfect JR, Heitman J: The calcineurin target Crz1, functions in azole tolerance but is not required for virulence of Candida albicans. Infect Immun 2004, 72:7330-7333.

24. Santos M, de Larrinoa IF: Functional characterization of the Candida albicans CRZ1 gene encoding a calcineurin-regulated transcription factor. Curr Genet 2005, 48:88-100.

25. Cramer RA Jr, Perfect BZ, Pinchai N, Park S, Perlin DS, Asfaw YG, Heitman J, Perfect JR, Steinbach WJ: Calcineurin Target CrzA Regulates Conidial Germination Hyphal Growth and Pathogenesis of Aspergillus fumigatus. Eukaryot Cell 2008, 7:1085-1097.

26. Da Silva Ferreira ME, Malavazi I, Savoldi M, Brakhage AA, Goldman MH, Kim HS, Nierman WC, Goldman GH: Transcriptome analysis of Aspergillus fumigatus exposed to voriconazole. Curr Genet 2006, 50:32-44.

27. Sales K, Brandt W, Rumbak E, Lindsey G: The LEA-like protein HSP 12 in Saccharomyces cerevisiae has a plasma membrane location and protects membranes against desiccation and ethanol-induced stress. Biochim Biophys Acta 2000, 1463:267-278.

28. Santhanam A, Hartley A, Duvel K, Broach JR, Garrett S: PP2A phosphatase activity is required for stress and Tor kinase regulation of yeast stress response factor Msn2p. Eukaryot Cell 2004, 3:1261-1271.

29. Lammers $\mathrm{T}$, Lavi S: Role of type $2 \mathrm{C}$ protein phosphatases in growth regulation and in cellular stress signaling. Crit Rev Biochem Mol Biol 2007, 42:437-461.

30. Yoshimoto H, Saltsman K, Gasch AP, Li HX, Ogawa N, Botstein D, Brown PO, Cyert MS: Genome-wide analysis of gene expression regulated by the calcineurin/Crz1p signaling pathway in Saccharomyces cerevisiae. J Biol Chem 2002, 277:31079-31088

31. Hagiwara D, Kondo A, Fujioka T, Abe K: Functional analysis of $\mathrm{C} 2 \mathrm{H} 2$ zinc finger transcription factor CrzA involved in calcium signaling in Aspergillus nidulans. Curr Genet 2008, 54:325-338.

32. Flipphi M, Kocialkowska J, Felenbok B: Characteristics of physiological inducers of the ethanol utilization (alc) pathway in Aspergillus nidulans. Biochem J 2002, 15:25-31.

33. Kingsbury $\mathrm{TJ}$, Cunningham KW: A conserved family of calcineurin regulators. Genes Dev 2000, 13:1595-1604.

34. Rothermel BA, Vega RB, Williams RS: The role of modulatory calcineurininteracting proteins in calcineurin signaling. Trends Cardiovasc Med 2003, 13:15-21.

35. Porta S, Serra SA, Huch M, Valverde MA, Llorens F, Estivill X, Arboné S, Martí E: RCAN1(DSCR1) increases neuronal susceptibility to oxidative stress a potential pathogenic process in neurodegeneration. Human Molecular Genetics 2007, 16:103-1050.

36. Vega RB, Rothermel BA, Weinheimer CJ, Kovacs A, Naseem RH, BasselDuby R, Williams RS, Olson EN: Dual roles of modulatory calcineurininteracting protein 1 in cardiac hypertrophy. Proceedings of the National Academy of Sciences of the United States of America 2003, 100:669-674.

37. Fox DS, Heitman J: Calcineurin-binding protein Cbp1 directs the specificity of calcineurin-dependent hyphal elongation during mating in Cryptococcus neoformans. Eukaryotic Cell 2005, 4:1526-1538.

38. Spielvogel A, Findon H, Arst HN, Araújo-Bazan L, Hernández-Ortí P, Stahl U, Meyer V, Espeso EA: Two zinc transcription factors CrzA and SItA are involved in cation homeostasis and detoxification in Aspergillus nidulans. Biochem J 2008, 414:419-429.

39. Hidalgo C, Donoso P: Crosstalk between calcium and redox signalling from molecular mechanisms to health implications. Antioxid Redox Signal 2008, 10:1275-1312.

40. Roderick HL, Cook SJ: $\mathrm{Ca}^{2+}$ signalling checkpoints in cancer remodeling $\mathrm{Ca}^{2+}$ for cancer cell proliferation and survival. Nat Rev Cancer 2008, 8:361375 .

41. Crawford DR, Leahy KP, Abramova N, Lan L, Wang Y, Davies KJA: Hamster adapt78 mRNA is a down syndrome critical region homologue that is inducible by oxidative stress. Arch Biochem Biophys 1997, 342:6-12. 
42. Leahy KP, Davies KJA, Dull M, Kort JJ, Lawrence KW, Crawford DA: Adapt78, a stress inducible mRNA is related to the glucose-related family of genes. Arch Biochem Biophys 1999, 368:6-12.

43. Ermak G, Harris CD, Davies KJA: The DSCR1 (Adapt78) isoform 1 protein calcipressin 1 inhibits calcineurin and protects against acute calciummediated stress damage including transient oxidative stress. The FASEB J 2002, 16:814-824.

44. Hilioti Z, Cunningham KW: The RCN family of calcineurin regulators. Biochem Biophys Res Commun 2003, 311:1089-1093.

45. Prelich G: Suppression mechanisms themes from variations. Trends Genet 1999, 15:261-266.

46. Horner VL, Czank A, Jang JK, Singh N, Williams BC, Puro J, Kubli E, Hanes SD, McKim KS, Wolfner MF, Goldberg ML: The Drosophila calcipressin sarah is required for several aspects of egg activation. Curr Biol 2006, 16:1441-1446.

47. Pinchai N, Perfect BZ, Juvvadi PR, Fortwendel JR, Cramer RA Jr, Asfaw YG, Heitman J, Perfect JR, Steinbach WJ: The Aspergillus fumigatus calcipressin $\mathrm{CbpA}$ is Involved in Hyphal Growth and Calcium Homeostasis. Eukaryotic Cell 2009, 8:511-519.

48. Kafer E: Meiotic and mitotic recombination in Aspergilllus and its chromosomal aberrations. Adv Genet 1977, 19:33-131.

49. Nayak T, Szewczyk E, Oakley CE, Osmani A, Ukil L, Murray SL, Hynes MJ, Osmani SA, Oakley BR: A versatile and efficient gene-targeting system for Aspergillus nidulans. Genetics 2006, 172:1557-1566.

50. Semighini CP, Marins M, Goldman MHS, Goldman GH: Quantitative analysis of the relative transcript levels of $A B C$ transporter Atr genes in Aspergillus nidulans by Real Time Reverse Transcripition PCR assay. Appl Environ Microbiol 2002, 68:1351-1357.

51. Bradford MM: A rapid and sensitive method for the quantification of microgram quantities of protein utilizing the principle of protein-dye binding. Anal Biochem 1976, 72:248-254.

52. Wang $\mathrm{JH}$, Pallen $\mathrm{CJ}$ : Calmodulin-stimulated dephosphorylation of $p$ nitrophenyl phosphate and free phosphotyrosine by calcineurin. J Biol Chem 1983, 258:8550-8553.

53. Malavazi I, Savoldi M, da Silva Ferreira ME, Soriani FM, Bonato PS, Goldman MHS, Goldman GH: Transcriptome analysis of the Aspergillus nidulans AtmA (ATM, Ataxia-Telangiectasia mutated) null mutant. $\mathrm{Mol}$ Microbiol 2007, 66:74-99.

54. Sambrook J, Russell DW: Molecular Cloning A Laboratory Manual. Cold Spring Harbor Laboratory Press. Cold Spring Harbor NY, 32001.

55. Colot HV, Park G, Turner GE, Ringelberg C, Crew CM, Litvinkova L, Weiss RL, Borkovich KA, Dunlap JC: A high-throughput gene knockout procedure for Neurospora reveals functions for multiple transcription factors. Proc Natl Acad Sci USA 2006, 103:10352-10357.

56. Chaveroche MK, Ghigo JM, d'Enfert C: A rapid method for efficient gene replacement in the filamentous fungus Aspergillus nidulans. Nucleic Acids Res 2000, 28:E97-E104.

57. Schiestl RH, Gietz RD: High efficiency transformation of intact yeast cells using single stranded nucleic acids as a carrier. Curr Genet 1989, 16:339-346.

58. Goldman GH, Reis dos, Marques E, Duarte Ribeiro DC, de Oliveira RC, Bernardes LA, Quiapin AC, Vitorelli PM, Savoldi M, Semighini CP, de Oliveira RC, Nunes LR, Travassos LR, Puccia R, Batista WL, Ferreira LE, Moreira JC, Bogossian AP, Tekaia F, Nobrega MP, Nobrega FG, Goldman $\mathrm{MH}$ : Expressed sequence tag analysis of the human pathogen Paracoccidioides brasiliensis yeast phase identification of putative homologues of Candida albicans virulence and pathogenicity genes. Eukaryot Cell 2003, 2:34-48.

59. Osmani SA, May GS, Morris NR: Regulation of the mRNA levels of $\operatorname{nimA}, \mathrm{a}$ gene required for the G2 M transition in Aspergillus nidulans. J Cell Biol 1987, 104:1495-1504.

\section{doi:10.1186/1471-2180-10-12}

Cite this article as: Soriani et al.: Identification of possible targets of the Aspergillus fumigatus CRZ1 homologue, CrzA. BMC Microbiology 2010 10:12. 